\title{
Life-style and travel demand
}

\section{From Special Report 220: A Look Ahead: Year 2020, Transportation Research Board, National Research Council, Washington, DC, 1988, pp. 149-189. Reproduced with permission of TRB}

\section{Ryuichi Kitamura}

Published online: 12 January 2010

(C) Transportation Research Board 1988

\begin{abstract}
Added to the original text) A fundamental solution to the issue of congestion cannot be reached without addressing the question of life-style. This paper reviews the definitions of life-style found in the literature, and identifies variables that have been commonly associated with life-style. Using US consumer expenditure data, life-styles are analyzed longitudinally (examining trends during the 1953-1983 time frame) and crosssectionally (comparing segments of the population stratified by income, life-cycle stage, and age), and likely relationships to travel behavior are noted. The usefulness of existing empirical findings to long-range forecasting is explored by speculating on shifts of behavioral units across life-style segments, and on shifts in the behavioral patterns within each life-style segment.
\end{abstract}

Keywords Lifestyle · Congestion · Travel behavior · Long-range forecasting

\section{Introduction}

To deal with the challenge to urban transportation, one must first recognize that congestion is not the problem, but merely a symptom. The true problem is the life-style to which Americans aspire; the American dream is to live in a suburban single-family house on a half-acre lot with a three-car garage. If this is the root of the urban transportation problem, then obviously a fundamental solution to the issue of congestion cannot be reached without addressing the question of life-style. The concept of life-style is important to travel behavior because the automobile, the dominant mode of urban travel today, is basic to the American life-style. As Flink (1987) notes, patterns of "courtship, residence, socialization of children, education, work habits, and use of leisure time were radically altered by the adoption of the automobile." The relationship of the automobile to American culture has inspired many authors. For example, focusing on "the car's role in the larger dream/ nightmare patterns dominating American life and thought," Dettelback (1976) notes that "as the most favored-and problematic_offspring of that particularly American union of

R. Kitamura $(\bowtie)$

University of California at Davis, Davis, CA, USA 
space, romance, and technology, the automobile occupies a central place in our fantasies as well as in our daily lives." If the American life-style is inspired by such fantasies, the automobile is an end in itself as well as a means.

Unfortunately, there has been no commonly accepted definition of the term "life-style" in the field of travel behavior analysis and demand forecasting. Little empirical evidence exists on how an individual acquires a particular life-style, how it is correlated with measurable attributes of the individual and his household, and how it is related to travel behavior. Nevertheless, the life-style concept extends the scope of travel behavior analysis and may possibly lead to improved predictive performance of forecasting models. For example, a recent analysis of trip generation behavior using longitudinal observations finds that there is an unexplained individual-specific effect, or idiosyncrasy (Kitamura 1988a). This idiosyncrasy, which is not explainable by sociodemographic variables, can be viewed as arising from the life-style of the individual.

The term "life-style" as used in the literature has two meanings: (a) activity and timeuse patterns and (b) values and behavioral orientation. These two are interrelated, but a critical difference exists: life-style as activity patterns may change as an individual adapts to a change in the environment, whereas life-style as orientation is one that the individual attempts to maintain by modifying behavioral patterns and adapting to the change. Change in life-style as orientation takes place in the long term through changes in values, attitudes, and preferences.

Life-style changes with socioeconomic, institutional, and technological changes. Increasing real income, decreasing working hours, and new consumer technology all contribute to the ever-evolving life-style of urban residents. The seemingly ever-expanding consumer demand leads to new products and services, industries and institutions, and urban forms. To gain an understanding of life-style and to develop the capability to predict its changes in the future, it is necessary to examine changes that take place in various elements of urban life and see how these changes are related to changes in life-style and travel behavior. This will constitute a basis for a more fundamental approach to long-range travel demand forecasting.

The objectives of this paper are (a) to offer a review of the monetary expenditure and travel characteristics of households across population subgroups defined in terms of variables believed to be correlated with life-style, (b) to determine the usefulness of this body of knowledge in long-term forecasting of travel demand, and (c) to identify factors that may influence life-style and travel behavior, but that have not been incorporated into travel behavior analysis and demand forecasting.

The paper is organized as follows. The definitions of life-style found in the literature are reviewed in the next section and variables that have been commonly associated with life-style are identified. Then the life-styles of population segments are reviewed using consumer expenditure statistics. The findings in the literature on travel characteristics of these segments are summarized; trends in the variables associated with life-style are reviewed, and likely changes in travel behavior are noted using the travel characteristics identified earlier. The discussion is extended to include those contributing factors that are typically not considered in travel behavior analysis. The last section presents conclusions and recommendations.

\section{What is life-style?}

Proposed definitions of life-style range from quantitative to conceptual. For example, Allaman et al. (1982) adopt a highly operational definition: Life-style "can be defined as 
how individuals and households allocate time to alternative activities such as work, inhome time, and recreation." Life-style, then, is a typology of time-use behavior.

Reichman's definition is similar (1975, pp. 143-152): "Households, or individuals, have established a certain life-style, or activity pattern, from which travel requirements are being derived." Life-style is again related to the individual's activities. Reichman's definition, however, extends beyond this (1977): "Life-styles are assumed to be shaped by recurrent behavioral responses to socioeconomic conditions, as well as to deeper personal or social attitudes, roles, or values." Life-style is thus seen to underlie travel behavior and is related to fundamental human values and needs. In particular, Reichman (1975) challenges the wisdom that travel demand is a derived demand: "Is transportation only a means to an end, or does it really fulfill some ends in itself?"

The definition by Reichman offers important implications. First, according to Reichman, life-style is not merely a typology of observed behavior but a latent factor that motivates behavior. Life-style thus defined is termed "life-style as behavioral orientation" as opposed to "life-style as a behavioral typology." Second, if an individual's travel behavior is driven by his life-style aspirations, adaptation behavior cannot be studied without knowledge of the values that the individual holds. Driving a car to work may not necessarily imply that driving has been chosen by an objective cost-benefit calculation of alternative modes; it may be an indication that the commuter assigns value to the act of driving itself.

Viewing life-style as a concept for broad characterization of households, Sharp (1979) defines life-style in terms of "a household's size and age, the social roles contained within it, the resources available to it, and the density and variety of activities open to it." This leads to a quite practical definition of life-style using life-cycle stage, income, and residential location. Life-cycle stage is viewed as "an indicator of the social roles present in different households, as well as the size and age of the household"; income represents available resources; and residential location is related to the accessibility to opportunities. Sharp thus defines life-style without reference to observed behavior; the definition is a typology of households, but not necessarily of their behavioral patterns.

Havens (1981) adopts the view that two societal factors, role and life-style, influence the demand for various types of activities and, consequently, influence travel behavior. A role is defined as "the set of behavior patterns and their associated societal norms that fulfills a function or set of functions" and life-style as "an ordered set of roles; the specific series of activities that fulfills them; and an individual's psychological orientation (values, attitudes, satisfaction, and dissatisfaction) to the activities." Again, life-style is not merely a behavioral pattern, but is tied to the individual's attitudes and values. As possible segmentation bases to obtain homogeneous life-style groups, Havens proposes social class, life-cycle stage, sex, minority status, and rural or urban residential location.

Salomon (1983), and Salomon and Ben-Akiva (1983) adopt a similar, but more specific, definition of life-style as "a pattern of behavior under constrained resources which conforms to the orientations an individual has toward three major 'life decisions' he or she must make: (a) formation of a household (of any type), (b) participation in the labor force, (c) orientation toward leisure." The choice of a life-style is viewed as a longer-term decision that conditions short-term decisions such as daily travel choices. Life-style is an observable behavioral pattern, but at the same time, it is an orientation that underlies behavior.

Common in most of these definitions is the notion that life-style is associated with behavioral patterns. In addition, life-style offers a useful conceptual framework as it relates to the individual's values or orientation, which is especially the case in the analysis of adaptation behavior. Using life-style as a framework, however, poses an immediate problem, 
because values and orientation are not measured in typical transportation surveys. Consequently, researchers have resorted to the use of population segments defined in terms of objective and frequently available person or household characteristics on the assumption that these segments offer internally homogeneous groups of behavioral units. Variables believed to causally influence behavior are chosen as segmentation bases-most frequently, life-cycle stage, employment status (or income or both), and sex. None of the studies reviewed in this section use perceptional or attitudinal data to define life-style segments.

Because of this difficulty in empirically investigating life-style as orientation, previous empirical analyses were concerned only with life-style as a typology of behavior. Although it is fully acknowledged that life-style as orientation offers a valuable conceptual framework, the usefulness of this notion in demand forecasting is limited if orientation needs to be inferred from revealed behavior. Furthermore, if the fundamental element that determines the individual's life-style orientation is the values that he or she holds, then an attempt to investigate the formation of life-style must address the question of how an individual forms his or her values, a task beyond the scope of typical transportation planning studies.

One obvious value of life-style as orientation is that it offers guidelines in defining the dimensions of analysis; life-style offers a theoretical medium that links revealed behavior and measurable characteristics of individuals. This undoubtedly is valuable in the construction of an analytical framework for travel behavior studies.

In the following two sections, life-style characteristics as revealed in consumer expenditures and travel patterns are discussed along the dimensions of life-cycle stage, age, employment, sex, income, car ownership, and license holding. Many of these parameters have been theorized to have a primary association with the individual's or household's lifestyle, whether as causal factors that condition and constrain life-style (e.g., income), as factors that determine or reflect roles (sex, employment, and life-cycle stages), or as the outcome of conscious life-style choices (e.g., employment status, presence of children, car ownership, and license holding).

\section{Life-style revealed by consumer expenditure patterns}

Published personal consumption expenditure statistics (Bureau of Economic Analysis 1986; Bureau of Labor Statistics 1986a, b) make up the database for this discussion. Historical trends in aggregate consumer expenditures are first examined with the intent of identifying long-term trends in lifestyle. Household expenditure patterns are then examined using income, life-cycle stage, and age as classifiers.

Because life-style as reflected in consumer expenditures is the subject of analysis, the following discussion does not immediately reveal the linkage between life-style and travel behavior. Nonetheless, monetary expenditures, similar to time use and trip generation, discussed in the next section, constitute one dimension along which urban life-styles may be characterized. The analysis in this section is motivated by the belief that an investigation of expenditure patterns of various population subgroups will aid in the determination of their life-style characteristics.

\section{Historical trends}

In the US, aggregate consumer expenditures on durable goods, non-durable goods, and services (expressed as a percentage of total expenditure in 1982 dollars) do not vary 
dramatically during the period 1953 through 1983 (Fig. 1). However, several moderate, but steady long-term trends exist that may extend into the near future.

The relative expenditure on durable goods shows a slight increase from $<10 \%$ of total consumption in the early 1950 s to more than $13 \%$ in the late 1970 s. The major changes in consumer expenditures are in the categories of non-durable goods and services; nondurable goods shows a decrease from around 48 to $38 \%$ during the 30 -year period. This decline is attributable mainly to a substantial decline in food expenditures. Service expenditures, on the other hand, show a steady increase from $42 \%$ in the early 1950 s to $50 \%$ in the 1980 s.

The increase in service expenditures is due primarily to increasing medical care and housing expenditures (Fig. 2). Interestingly, the increase in housing and medical care expenditures approximately equals the decline in food expenditures. As a result, the total expenditure for these three categories of subsistence items remained virtually unchanged over time (Fig. 3), and so does the relative budget size for discretionary activities. This is shown by recreational expenditures, perhaps the most discretionary, which remained stable at around $2 \%$ of the total expenditure, except for a slight increase from the beginning of the 1970s.

In addition, educational expenditures remained around the $2 \%$ range, with a slight decline since the 1970s. Expenditures in personal care declined, which may be a reflection of the prevalence of casual life-styles. The relative expenditure on clothing, which also declined gradually until 1970, started to increase afterward.

Motor vehicle consumption conforms to the stable pattern shown for expenditures on non-durable goods; it increases from $<5 \%$ in the early 1950 s to more than $6 \%$ in the late 1970s (Fig. 4). The decline in the early 1980s is presumably a reflection of the economic depression during that period. Expenditures on transportation services (mainly public transit, including air) fluctuate, but do not exhibit any trend. Consumption of gasoline remained stable over the three decades despite the two oil embargoes, with a minimum of $4.35 \%$ observed in 1981 and 1982, and a maximum of 5.43\% in 1971. Overall transportation expenditures remained stable except for the peaks around 1973 and 1977, which are primarily due to the increased expenditures on motor vehicles, as Fig. 4 clearly shows.

In summary, the relative share of food in the total consumer expenditures declined during the three decades starting in 1953, but this decline is offset by increases in housing

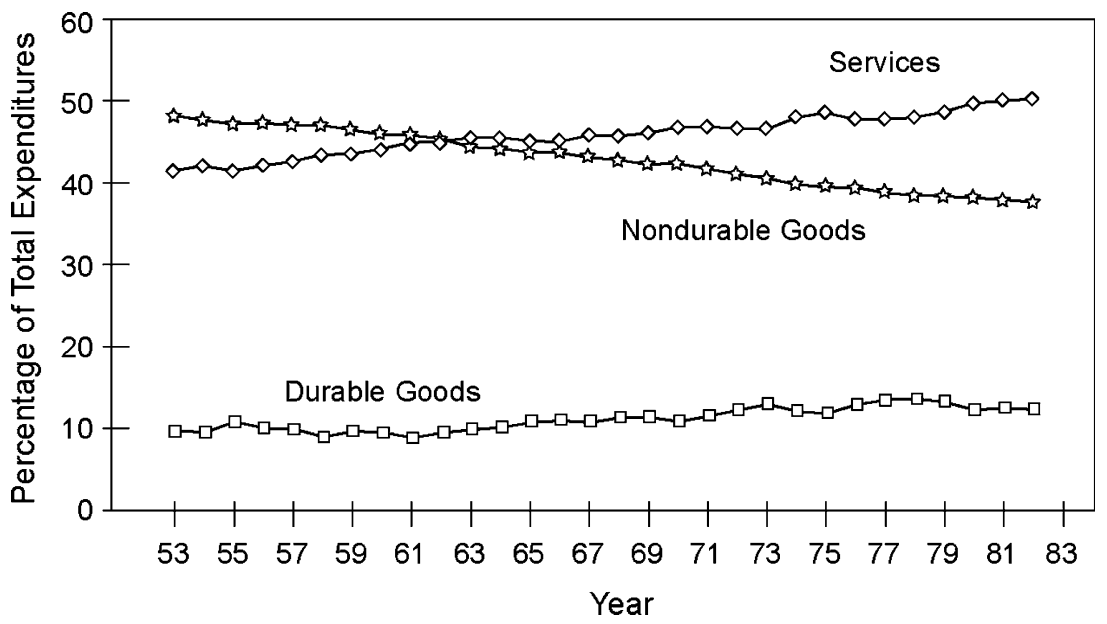

Fig. 1 Consumer expenditure on durable and non-durable goods and services 


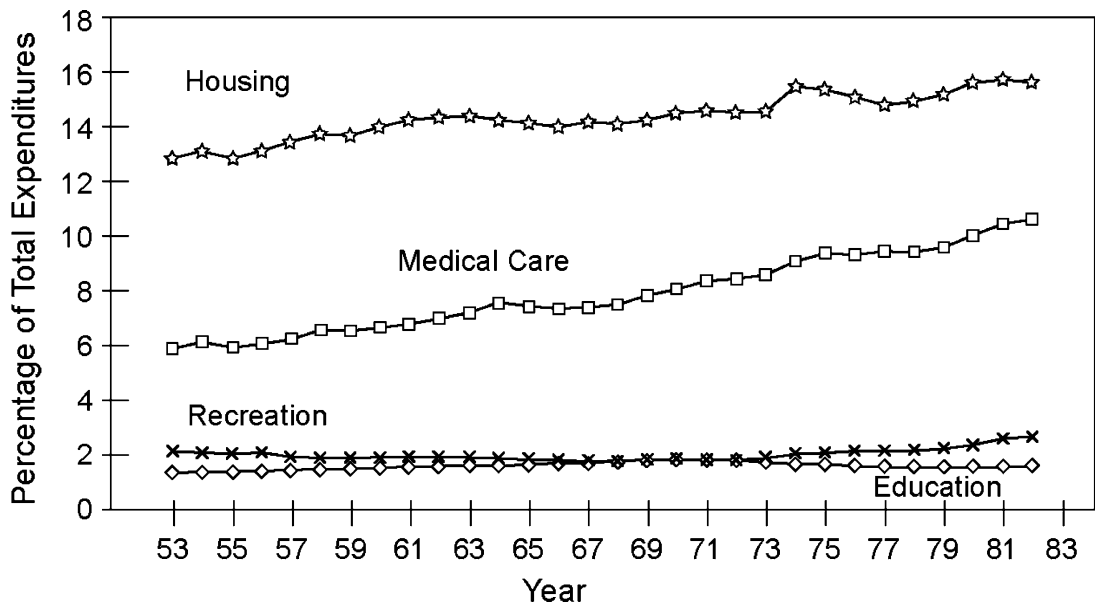

Fig. 2 Relative expenditures on housing, medical care, recreation and education

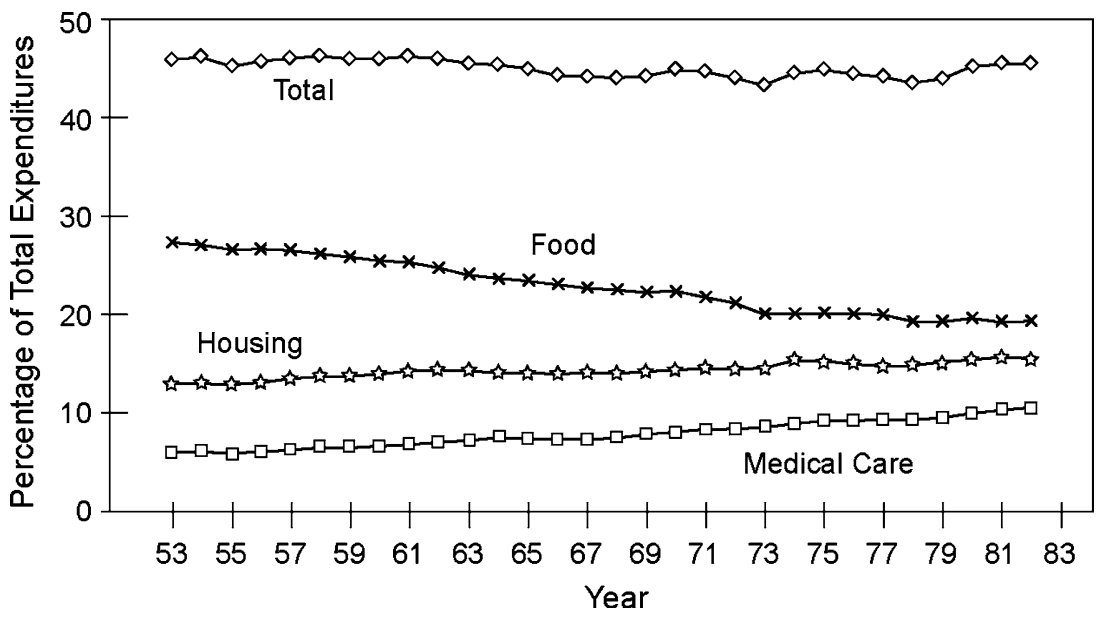

Fig. 3 Stability in expenditures on housing, medical care and food

and medical care. The share of transportation expenditures has been surprisingly stable despite the two energy crises in the 1970s. Expenditures on recreation also remained stable. Notable changes are all in expenditures at the subsistence level and little has changed in discretionary expenditures. The relative expenditure figures used in this analysis do not represent precisely what the consumer was able to purchase for the money. Nevertheless, if the relative expenditures are correlated with life-style, the trends just outlined suggest that consumer life-style has been very stable during the past three decades.

Income

Longitudinal stability in life-style does not necessarily imply cross-sectional uniformity. The remainder of this discussion is based on the published results of a 1982-1983 survey of 


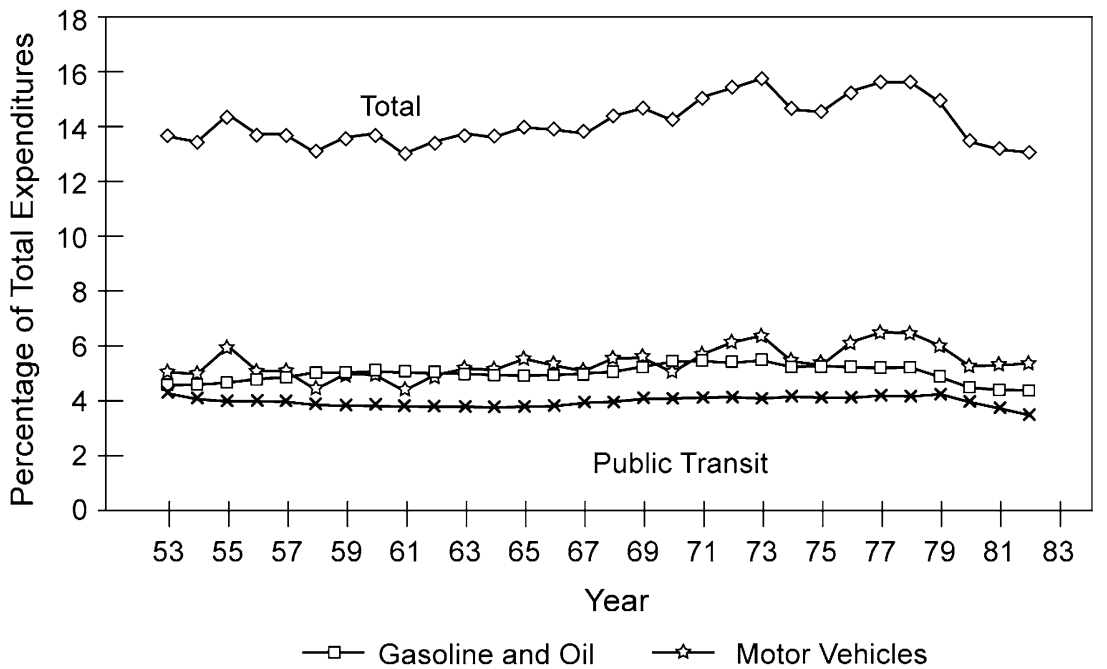

Fig. 4 Transportation-related consumer expenditures

consumer expenditures (Bureau of Labor Statistics 1986a, b). The effect of income on expenditures can be seen in Table 1, where relative expenditures as percentages of the total expenditure are presented by quintiles of household income before taxes. The average total expenditure varies across the five groups shown from $\$ 8,324$ to $\$ 35,171$ per household per year. If income can be viewed as "a surrogate for the propensity of the individual to spend time out of home" for activities (Brail and Chapin 1973), variations in expenditure patterns along the dimension of income should reveal a relationship between life-style orientation and income that is relevant for travel demand analysis.

An inspection of Table 1 immediately reveals several well-acknowledged relations. The relative expenditure on food decreased with increasing income. Housing expenditures show the same tendency, with expenditure on rented dwellings diminishing as income increases. The relative expenditure on health care also decreases with income, whereas that on clothing is stable.

Of particular interest in travel behavior analysis are expenditures on food away from home (FAFH), transportation, and entertainment. Regardless of the total income, the relative FAFH expenditures are stable at around 5\% of the total. In terms of absolute values, however, the highest-income group spent four times as much on FAFH as did the lowestincome group, reflecting obvious differences in life-style across income groups and supporting the previous finding that higher-income groups make a larger number of eat-meal trips (Allaman et al. 1982).

Higher-income households spend more on entertainment, in both absolute and relative terms. Although the historical trend does not indicate substantial longitudinal changes in expenditures in this category, the presence of cross-sectional variations is evident. The result suggests that the orientation toward leisure is strongly correlated with income.

Relative expenditures on transportation exhibit only weak correlations with income, except for the very low expenditure by the lowest-income group. In terms of the absolute amount of expenditure, the highest-income group spent three times as much on transportation as did the lowest-income group (Table 2). The average annual expenditure on automobiles ranges from $\$ 385$ for the lowest-income group to $\$ 3,202$ for the 
Table 1 Annual expenditures of urban households by quintiles of income before taxes, 1982-1983: percentage of total expenditure (Bureau of Labor Statistics 1986b, Table 1)

\begin{tabular}{lrrrrr}
\hline Household size & 1.8 & 2.3 & 2.6 & 3.0 & 3.3 \\
No. of workers & 0.6 & 1.0 & 1.3 & 1.7 & 2.1 \\
Age of reference person & 49.9 & 48.7 & 43.8 & 42.3 & 44.3 \\
No. of children under 18 & 0.4 & 0.6 & 0.8 & 0.9 & 0.9 \\
No. of persons over 65 & 0.4 & 0.5 & 0.3 & 0.2 & 0.1 \\
No. of cars available & 0.8 & 1.3 & 1.8 & 2.3 & 2.8 \\
Income before taxes $(\$)$ & 4,097 & 10,611 & 18,129 & 28,231 & 52,267 \\
Total expenditure $(\$)$ & 8,324 & 12,155 & 16,733 & 22,425 & 35,171 \\
\hline
\end{tabular}

Expenditure category

Income quintile

Lowest $20 \%$

Highest $20 \%$

\begin{tabular}{|c|c|c|c|c|c|}
\hline Food & 21.1 & 19.2 & 17.2 & 16.1 & 13.7 \\
\hline Food at home & 15.9 & 14.7 & 12.4 & 11.3 & 8.8 \\
\hline $\begin{array}{l}\text { Food away from home } \\
\text { (FAFH) }\end{array}$ & 5.1 & 4.5 & 4.8 & 4.8 & 4.9 \\
\hline Alcoholic beverages & 1.6 & 1.6 & 1.6 & 1.6 & 1.3 \\
\hline Housing & 35.8 & 32.9 & 30.1 & 28.8 & 29.0 \\
\hline Shelter & 20.8 & 18.1 & 16.9 & 16.2 & 16.6 \\
\hline Own dwelling & 7.0 & 6.9 & 7.9 & 9.9 & 12.7 \\
\hline Rented dwelling & 12.3 & 10.3 & 7.9 & 5.0 & 1.8 \\
\hline Other lodging & 1.4 & 1.0 & 1.1 & 1.3 & 2.1 \\
\hline $\begin{array}{l}\text { Utilities, fuels, public } \\
\text { services }\end{array}$ & 10.8 & 10.1 & 8.3 & 7.4 & 6.0 \\
\hline Household operations & 1.5 & 1.3 & 1.2 & 1.3 & 1.6 \\
\hline $\begin{array}{l}\text { House furnishing and } \\
\text { equipment }\end{array}$ & 2.7 & 3.4 & 3.7 & 3.9 & 4.7 \\
\hline Apparel & 5.2 & 5.0 & 5.2 & 5.2 & 5.8 \\
\hline Men and boys & 1.1 & 1.1 & 1.2 & 1.3 & 1.6 \\
\hline Women and girls & 2.1 & 2.0 & 2.0 & 2.0 & 2.4 \\
\hline Other & 2.0 & 2.0 & 1.9 & 1.8 & 1.9 \\
\hline Transportation & 14.8 & 18.6 & 20.6 & 20.5 & 19.8 \\
\hline $\begin{array}{l}\text { Cars and trucks, new (net } \\
\text { outlay) }\end{array}$ & 1.0 & 2.6 & 3.4 & 4.2 & 5.4 \\
\hline $\begin{array}{l}\text { Cars and trucks, used (net } \\
\text { outlay) }\end{array}$ & 3.2 & 3.2 & 3.8 & 3.2 & 2.7 \\
\hline Vehicle finance charges & 0.4 & 0.6 & 1.0 & 1.0 & 1.0 \\
\hline Gasoline and motor oil & 5.2 & 6.3 & 6.3 & 6.0 & 4.8 \\
\hline $\begin{array}{l}\text { Maintenance, repairs, } \\
\text { insurance }\end{array}$ & 3.2 & 4.1 & 4.3 & 4.3 & 3.8 \\
\hline Public transit & 1.3 & 1.2 & 1.1 & 1.0 & 1.3 \\
\hline Other & 0.5 & 0.6 & 0.8 & 0.8 & 0.8 \\
\hline Health care & 6.2 & 6.6 & 4.9 & 3.9 & 3.1 \\
\hline Entertainment & 3.4 & 3.5 & 4.2 & 5.0 & 5.3 \\
\hline Fees and admissions & 1.1 & 1.0 & 1.3 & 1.5 & 1.9 \\
\hline
\end{tabular}


Table 1 continued

\begin{tabular}{lllllr}
\hline Television, radios, sound equipment & 1.3 & 1.5 & 1.5 & 1.6 & 1.5 \\
Other equipment and services & 1.0 & 1.1 & 1.4 & 1.9 & 1.9 \\
Personal care & 1.0 & 1.0 & 0.9 & 0.9 & 0.9 \\
Reading & 0.7 & 0.7 & 0.7 & 0.7 & 0.6 \\
Education & 3.2 & 1.0 & 0.8 & 0.9 & 1.6 \\
Tobacco and smoking supplies & 1.5 & 1.5 & 1.3 & 1.2 & 0.7 \\
Miscellaneous & 1.6 & 1.3 & 1.4 & 1.5 & 1.5 \\
Cash contributions & 1.7 & 2.2 & 3.2 & 3.1 & 3.9 \\
Personal insurance and pensions & 2.3 & 4.7 & 7.8 & 10.5 & 12.9 \\
\hline
\end{tabular}

Table 2 Annual transportation expenditures of urban households by quintiles of income before taxes, 1982-1983: percentage of total expenditure (Bureau of Labor Statistics 1986b, Table 1)

\begin{tabular}{lrrrrrr}
\hline Expenditure category & \multicolumn{7}{l}{ Expenditure (\$) by income quintile } \\
\cline { 2 - 7 } & \multicolumn{7}{l}{ Lowest 20\% } & & Highest 20\% & Total \\
\hline Cars and trucks, new (net outlay) & 81 & 311 & 566 & 942 & 1,914 & 764 \\
Cars and trucks, used (net outlay) & 268 & 386 & 640 & 716 & 934 & 589 \\
Vehicle finance charges & 36 & 78 & 159 & 232 & 354 & 172 \\
Gasoline and motor oil & 429 & 763 & 1,062 & 1,351 & 1,692 & 1,060 \\
Maintenance, repairs, insurance & 269 & 502 & 722 & 958 & 1,320 & 755 \\
Public transit & 105 & 149 & 176 & 222 & 461 & 223 \\
Other & 43 & 70 & 126 & 183 & 275 & 140 \\
Total & 1,231 & 2,259 & 3,451 & 4,604 & 6,950 & 3,703 \\
\hline
\end{tabular}

highest-income group. The average number of automobiles available varies from 0.8 to 2.8 across income groups, with the average expenditure per vehicle ranging from $\$ 480$ to $\$ 1,150$ a year.

The relative share of the expenditure on gasoline shows a weak association with income (Table 1). The absolute amount of expenditure, however, ranges from $\$ 429$ to $\$ 1,692$ a year across income groups. Gasoline expenditure per vehicle has a small range of $\$ 536$ to $\$ 608$ per vehicle per year, with the expenditure increasing with income. High-income households tend to own more automobiles and to use each of these automobiles slightly more extensively than do low-income households (this tendency may in fact be more pronounced if high-income households, which are capable of replacing their automobiles more frequently, tend to own newer, more fuel-efficient automobiles). The result is consistent with the well-accepted finding that travel time budgets and vehicle use increase with income (Brail and Chapin 1973; Gunn 1981; Hanson and Hanson 1981a; Pendergast and Williams 1981).

Lower-income groups have higher shares of expenditure on non-private transportation, indicating their dependence on public transit. The absolute amount of expenditure, however, again increases with income. This may be due to long-distance commuting and intercity travel by air by the higher income groups, although available data are not sufficient to determine the exact causes.

It is evident that income has a predominant impact on household expenditure; higherincome households spend substantially larger amounts on food away from home, 
entertainment, automobiles, and gasoline. Higher income seems to be accompanied by a distinct life-style. This result must be critically evaluated, however; many past analyses of trip generation indicated that income is not a primary determinant of trip generation (Allaman et al. 1982; Kostyniuk and Kitamura 1986a). The ineffectiveness of income is in part due to the fact that car ownership, which is strongly correlated with income, represents a household's long-term mobility choice and therefore better accounts for observed travel behavior than does income. Indeed, past results suggest that trip generation is conditionally independent of income, given car ownership. The foregoing analysis, on the other hand, has shown that income is strongly tied to expenditures on items that lead to trip making, for example, food away from home and entertainment. Further analysis is clearly needed on the linkage between life-style (as reflected in consumer expenditure patterns) and travel behavior, in particular trip generation.

\section{Life-cycle stage}

The use of the life-cycle concept in transportation planning studies dates back to the 1960s when a set of trip generation models was formulated using life-cycle stages in the Detroit Transportation and Land Use Study (TALUS) (Ladd et al. 1969). A 1971, 35-day travel diary survey in Uppsala, Sweden, used life-cycle stages as the basis for its stratified sampling (Hanson and Hanson 1981a). Recent examples include the ongoing Dutch National Mobility Panel survey, which also employs a stratified sampling scheme using life-cycle stages (Golob et al. 1986). Extensive efforts were made in the late 1970s to early 1980 s to investigate the relationship between the life-cycle stage of a household and the travel behavior of its members (Allaman et al. 1982; Chapin 1978; McGinnis 1978; Chicoine and Boyle 1984; Damm 1983; de La Morsangliere and Raux 1983: Golob and Zondag 1983; Hanson and Hanson 1981a; Jones et al. 1983; Kitamura 1983; Kostyniuk and Cleveland 1978; Kostyniuk and Kitamura 1982, 1984, 1986b; Pas 1984; Sharp 1979; Simonsen and Neveu 1985; Skinner 1984; Stopher and Ergun 1979; Zimmerman 1982).

Behind this historical use of life-cycle variables is the fact that life-cycle stages provide "a convenient base for empirical analysis, a composite variable combining imperfectly, but adequately many of the major sources of variation among households" (Jones et al. 1983). Typically defined in terms of the age and marital status of the adult members and the presence and age of the children of a household, life-cycle stages are viewed as indicators of the needs and constraints governing activity and trip making.

The role most clearly defined by life-cycle stage is that of child rearing. It is not difficult to imagine how this role may shape and constrain the activity and travel behavior of adult family members, especially mothers. In reference to the contributions made by activitybased approaches to travel behavior (Damm 1983; Jones et al. 1983; Kitamura 1988b; Pas 1985), it is noted that (Goodwin 1983) “the single most important 'discovery' of activity work to date has been the importance of children, not primarily because of their own trips... but because the very fact of children in a household imposes highly complex and binding constraints on the activities and travel patterns of all other members of the households."

Life-cycle stages define an axis for travel behavior analysis because of its association with various roles that a household and its members play. As discussed earlier, marriage (or cohabitation), another parameter that defines life-cycle stages, leads to the assignment of bread-winning and homemaking roles between men and women. Therefore, if life-style is interpreted as "an ordered set of roles" (Salomon 1983), a fundamental association must exist between life-cycle and life-style. 
Consumer expenditure patterns are presented by household structure in Table 3, where households are classified by the presence of children by age group and by the marital status of the adult members. This categorization in a published tabulation (Bureau of Labor Statistics 1986a, b) does not precisely represent stages in the life-cycle, because the first category in Table 3, couples without children, includes both young couples before they have children and older couples who hold "empty nests." Similarly, the last category, singles, includes both young individuals before marriage and those who do not marry. Nonetheless, the expenditure patterns shown in the table offer certain variations that are indicative of changes in life-style along life-cycle stages.

\section{Households with children}

Total transportation expenditures increase toward the last stage of child rearing in both absolute and relative terms. This is in agreement with findings obtained from analyses of travel patterns (Denk and Boyle 1982; Kitamura 1983; Kostyniuk and Kitamura 1986b; McGinnis 1978). Mean car ownership, gasoline expenditure, and gasoline expenditure per person all show the same tendency and peak among the households with the oldest children (18 years or older). Furthermore, income and expenditures on food, apparel, personal care, reading, and education all follow the same pattern; a broad range of a household's mobility and activity levels reaches a peak as its oldest child becomes 18 .

An interesting exception is housing expenditures, which are highest among households in the earliest stage of child rearing, when the oldest child is $<6$ years of age. This is presumably based on the group of young households that acquired a home recently after home ownership costs increased substantially (see Fig. 2). Another important exception is entertainment expenditures, which peak among households in which the oldest children are between 6 and 17. This presumably reflects the entertainment needs of school-age children.

\section{Couples without children}

The expenditure pattern of the first category in Table 3, husband-wife couples with no children, differs in several important ways from the pattern shown by the second category, couples whose oldest child is $<6$. The expenditures on FAFH of the former group are much larger than those of the latter group in both absolute and relative terms; their average FAFH expenditure per person ( $\$ 531$ per year) is the highest among the groups, exceeding those of the four household groups with children $(\$ 213, \$ 263, \$ 364$, and $\$ 182$, respectively); the single person (\$505), and single parents (\$199). Dining out is part of the life-style associated with couples without children.

Couples without children on average spend larger proportions of their income on new automobiles, house furnishing, personal care, reading, and health care than do any other groups shown in Table 3. The first two items indicate that many couples in this group are starting new households, whereas the large share for health care suggests that the group contains older couples who have passed the child-rearing stage. Unfortunately, expenditure patterns of these two subgroups cannot be determined from the available tabulation.

\section{Single individuals}

The expenditure pattern of the last group in Table 3, single persons and other households without children, can be characterized by the large per-person expenditures on FAFH and alcoholic beverages, suggesting the outward orientation of their life-style. The share of 
Table 3 Annual expenditures of urban households by household structure, 1982-1983 (Bureau of Labor Statistics 1986b, Table 5)

\begin{tabular}{lrrrrrrr}
\hline Household size & 2.0 & 3.5 & 4.2 & 4.0 & 5.2 & 3.0 & 1.5 \\
No. of workers & 1.2 & 1.6 & 1.7 & 2.7 & 2.4 & 1.0 & 0.9 \\
Age of reference person & 54.4 & 29.9 & 38.3 & 52.3 & 47.7 & 35.4 & 47.4 \\
No. of children under 18 & & 1.5 & 2.2 & 0.6 & 1.6 & 1.8 & 0.1 \\
No. of persons 65 and over & 0.6 & & & 0.2 & 0.5 & & 0.3 \\
No. of cars available & 2.0 & 2.0 & 2.5 & 3.2 & 2.6 & 1.0 & 1.1 \\
Income before taxes (\$) & 26,010 & 27,356 & 31,153 & 37,037 & 30,561 & 12,939 & 14,684 \\
Income after taxes (\$) & 22,938 & 24,440 & 27,864 & 32,967 & 26,934 & 12,111 & 12,991 \\
\hline
\end{tabular}

Expenditure category Expenditure $(\$)$ by household structure

$$
\text { Husband and wife }
$$

No child Child
$<6$

Food
Food at home
Food away from home
(FAFH)

Alcoholic beverages

Housing

Shelter

Own dwelling

Rented dwelling

Other lodging

Utilities, fuels, public services

Household operations

House furnishing and equipment

Apparel

Men and boys

Women and girls

Others

\section{Transportation}

Cars and trucks, new (net outlay)

Cars and trucks, used (net outlay)

Vehicle finance charges

Gasoline and motor oil

Maintenance, repairs, insurance

Public transit

Other

Health care

Entertainment

3,210
2,148
1,06

302

6,294

3,424

2,237

772

415

1,605

242

1,023

1,042

252

441

349

4,154

1,063

548

155

1,108

819

299

162

1,178

934

3,241

2,492

7,863

4,533

3,046

1,264

222

1,554

$$
792
$$

262

Child

Child $\geq 18$

Single

Single

parent person

Other

units

$4,445 \quad 5,093$

4,397

2,759

2,064

3,340

3,638

3,449

2,161

1,305

748

1,105

1,455

948

598

758

264

277

328

288

145

292

7,756

7,208

6,805

4,748

4,131

4,378

3,632

3,402

2,620

2,540

3,341

2,686

2,282

1,053

925

688

399

692

1,446

1,427

546

429

121

188

1,933

2,252

2,091

1,392

1,021

421

211

339

309

142

429

$1,107 \quad 1,478$

1,114

973

427

687

157

413

1,639

1,364

907

343600

465

349

183

272

$502 \quad 465$

490

520

415

258

$4,085 \quad 5,046$

6,319

495

309

2,404

$743 \quad 1,202$

1,135

5,007

2,130

451

$845 \quad 850$

1,110

579

471

384

$217 \quad 267$

318

$$
278
$$

105

97

$1,165 \quad 1,454$

1,919

1,630

680

672

$773 \quad 915$

1,359

1,111

443

491

$182 \quad 194$

$$
269
$$

277

177

203

$160 \quad 164$

209

139

67

106

$789 \quad 867$

1,097

1,186

480

562

$1,010 \quad 1,476$

1,243

1,026

590

528


Table 3 continued

\begin{tabular}{lrrrrrrr}
\hline Fees and admissions & 342 & 254 & 461 & 412 & 312 & 194 & 181 \\
Television, radios, sound equipment & 278 & 311 & 459 & 403 & 356 & 204 & 190 \\
Other equipment and services & 313 & 445 & 557 & 428 & 358 & 192 & 156 \\
Personal care & 220 & 150 & 216 & 288 & 237 & 136 & 115 \\
Reading & 160 & 126 & 154 & 173 & 131 & 75 & 94 \\
Education & 145 & 98 & 374 & 863 & 291 & 179 & 213 \\
Tobacco and smoking supplies & 209 & 194 & 250 & 315 & 355 & 166 & 152 \\
Miscellaneous & 278 & 240 & 296 & 361 & 384 & 223 & 234 \\
Cash contributions & 824 & 365 & 603 & 1,142 & 618 & 259 & 376 \\
Personal insurance and pensions & 1,975 & 2,023 & 2,367 & 2,814 & 2,175 & 798 & 879 \\
Total & 20,926 & 21,555 & 25,606 & 28,884 & 24,264 & 13,595 & 12,732 \\
\hline
\end{tabular}

expenditures on non-private transportation of this group (1.6\%) is the largest of the seven groups. The group's average expenditure on own dwellings is the lowest and that on rented dwellings is the second highest. The group is mobile; its average per-person gasoline expenditure (\$448) is among the highest, next only to that of couples without children (\$554). The discussion here is again limited, because a distinction between young and old single-person households cannot be made from the available data.

\section{Single parents}

This group has the smallest income and smallest expenditures on FAFH, alcoholic beverages, new automobiles, health care, and reading. The fraction of renters is high, average per-person recreational expenditure is low, and the relative share of food expenditures is the highest among the seven household groups. The expenditure pattern thus offers indications of the poor economic status of this group, as is often noted in the literature (McKnight et al. 1986; Raux and Rosenbloom 1986; Rosenbloom 1985; Rutherford and Wekerle 1986).

This group has the lowest level of car ownership, smallest average per person expenditure on gasoline, and smallest expenditure on automobiles. The consumer expenditure pattern thus suggests that single-parent households are the least mobile among the groups studied here.

Age

Household income and expenditure peak when the representative household member is 4554 years old (Table 4). Expenditures on food, transportation, and personal insurance and pensions have a similar peak, whereas housing and entertainment expenditures peak at 3544 years. The youngest group $(<25)$ and oldest group $(65$ and over) have similar total expenditure levels, but their budget allocations are different; the younger group spends more on FAFH, alcoholic beverages, transportation, and entertainment. Health-care expenditures increase substantially and expenditures on alcoholic beverages decrease with age. The share of apparel in the total expenditure also decreases with age.

The expenditure patterns shown in Table 4 are consistent with the common finding that the mobility of individuals peaks when they are in their 30s and 40s, and that the elderly are the least mobile (Levinson 1976). It appears that households go through a period of 
Table 4 Annual expenditures of urban households by age of reference person, 1982-1983 (Bureau of Labor Statistics 1986b, Table 3)

\begin{tabular}{lrrrrrrr}
\hline Household size & 1.8 & 2.7 & 3.5 & 3.2 & 2.4 & 1.7 & 2.6 \\
No. of workers & 1.2 & 1.4 & 1.8 & 2.0 & 1.4 & 0.4 & 1.3 \\
Age of reference person & 21.7 & 29.7 & 39.0 & 49.6 & 59.4 & 73.4 & 46.2 \\
No. of children under 18 & 0.3 & 1.0 & 1.5 & 0.7 & 0.2 & 0.1 & 0.7 \\
No. of persons 65 and over & & & & 0.1 & 0.1 & 1.4 & 0.3 \\
No. of cars available & 1.1 & 1.8 & 2.2 & 2.5 & 2.0 & 1.1 & 1.8 \\
Income before taxes (\$) & 11,537 & 23,835 & 29,718 & 31,198 & 24,450 & 13,583 & 22,702 \\
Income after taxes (\$) & 10,282 & 20,992 & 26,455 & 27,068 & 21,865 & 12,739 & 20,182 \\
\hline
\end{tabular}

\begin{tabular}{|c|c|c|c|c|c|c|c|}
\hline & \multicolumn{7}{|c|}{ Expenditure (\$) by age of reference person } \\
\hline & $<25$ & $25-34$ & $35-44$ & $45-54$ & $55-64$ & $\geq 65$ & Total \\
\hline Food & 1,835 & 2,949 & 4,046 & 4,166 & 3,328 & 2,288 & 3,137 \\
\hline Food at home & 1,163 & 2,011 & 2,894 & 2,938 & 2,326 & 1,700 & 2,204 \\
\hline $\begin{array}{l}\text { Food away from home } \\
\text { (FAFH) }\end{array}$ & 672 & 938 & 1,152 & 1,228 & 1,002 & 588 & 933 \\
\hline Alcoholic beverages & 343 & 356 & 322 & 307 & 260 & 133 & 285 \\
\hline Housing & 3,410 & 6,409 & 7,494 & 6,870 & 5,374 & 4,123 & 5,784 \\
\hline Shelter & 2,151 & 3,915 & 4,411 & 3,658 & 2,697 & 2,073 & 3,262 \\
\hline $\begin{array}{l}\text { Utilities, fuels, public } \\
\text { services }\end{array}$ & 668 & 1,305 & 1,789 & 1,969 & 1,701 & 1,342 & 1,489 \\
\hline Household operations & 115 & 359 & 327 & 226 & 208 & 267 & 271 \\
\hline $\begin{array}{l}\text { House furnishing and } \\
\text { equipment }\end{array}$ & 475 & 831 & 968 & 1,016 & 767 & 440 & 762 \\
\hline Apparel & 782 & 1,071 & 1,428 & 1,366 & 993 & 515 & 1,030 \\
\hline Transportation & 2,623 & 4,052 & 4,758 & 4,991 & 3,656 & 1,972 & 3,712 \\
\hline $\begin{array}{l}\text { Cars and trucks (net } \\
\text { outlay }+ \text { finance charges) }\end{array}$ & 1,184 & 1,913 & 2,174 & 2,048 & 1,297 & 641 & 1,572 \\
\hline Gasoline and motor oil & 745 & 1,073 & 1,308 & 1,493 & 1,145 & 603 & 1,062 \\
\hline $\begin{array}{l}\text { Maintenance, repairs, } \\
\text { insurance }\end{array}$ & 318 & 423 & 538 & 585 & 457 & 258 & 430 \\
\hline Public transit & 126 & 229 & 253 & 267 & 281 & 189 & 228 \\
\hline Other & 250 & 414 & 485 & 598 & 476 & 281 & 420 \\
\hline Health care & 307 & 547 & 753 & 936 & 1,056 & 1,228 & 822 \\
\hline Entertainment & 581 & 977 & 1,294 & 1,075 & 799 & 390 & 870 \\
\hline Fees and admissions & 186 & 273 & 413 & 386 & 289 & 163 & 287 \\
\hline $\begin{array}{l}\text { Television, radios, sound } \\
\text { equipment }\end{array}$ & 223 & 317 & 420 & 338 & 233 & 136 & 282 \\
\hline $\begin{array}{l}\text { Other equipment and } \\
\text { services }\end{array}$ & 172 & 387 & 461 & 351 & 277 & 90 & 301 \\
\hline Personal care & 92 & 148 & 203 & 223 & 213 & 166 & 176 \\
\hline Reading & 74 & 121 & 154 & 153 & 140 & 106 & 127 \\
\hline Education & 489 & 180 & 343 & 590 & 197 & 45 & 274 \\
\hline $\begin{array}{l}\text { Tobacco and smoking } \\
\text { supplies }\end{array}$ & 139 & 196 & 249 & 290 & 244 & 116 & 205 \\
\hline Miscellaneous & 119 & 244 & 347 & 356 & 329 & 198 & 270 \\
\hline
\end{tabular}


Table 4 continued

\begin{tabular}{lrrrrrrr}
\hline Cash contributions & 100 & 297 & 695 & 925 & 754 & 665 & 576 \\
Personal insurance and pensions & 722 & 1,724 & 2,209 & 2,469 & 2,155 & 401 & 1,625 \\
Total & 11,617 & 19,271 & 24,296 & 24,718 & 19,497 & 12,346 & 18,892 \\
\hline
\end{tabular}

expansion in their expenditures and then a period of contraction. The life-style of a household, then, changes as it ages and progresses through the life-cycle stages. At the same time, it is plausible that individuals in the same age group share certain life-style traits that are maintained over time despite their aging (i.e., a cohort effect), thus leading to the emergence of new life-styles as these individuals enter later stages of the life-cycle (Kostyniuk and Kitamura 1987; Bunker et al. 1977; Wachs and Blanchard 1976).

\section{Summary}

Household expenditure patterns have been shown to vary by income, life-cycle stage, and age. These results are generally in agreement with common findings from travel behavior research. In addition, expenditure patterns for automobiles, gasoline, housing, entertainment, and food away from home, which are not generally available from transportation surveys, have been described. With these expenditure characteristics of population subgroups as background, the discussion now turns to travel characteristics of urban residents.

\section{What is known about travel behavior?}

The discussion in this section is motivated by the question: What is known about the association between travel behavior and those parameters that are believed to be associated with life-style? A review is presented of findings available in the literature on travel characteristics of various population subgroups. The measures of behavior used in the discussion include trip rate, trip distance, travel-time budget (expenditure), mode use, and time use.

There exists a set of factors that are believed to constrain and direct an individual's activity choice and life-style. They consist of (Chapin 1978) "certain personal characteristics (e.g., sex, stage in the life cycle, and health status) and roles that society assigns to persons (e.g., the bread-winning role long assumed in Western countries by the male partner of the household and the homemaking role by the female partner)." This, combined with the emphasis of this study on anticipated demographic changes and likely shifts in life-style, has led to the use of life-cycle stage, sex, employment, age, income, and car ownership in the analysis of this section. These variables have quite often been used in sample segmentation with the intent of creating subgroups with internally homogeneous life-styles. Ethnicity and education are also used occasionally as segmentation bases. It has been claimed that (Kostyniuk and Cleveland 1978) "significant behavioral variations, which may result from differences in tastes, motivations, and personalities, may be captured through population segmentation" using these variables.

Life-cycle subgroups

Empirical results from past analyses of urban household travel behavior exhibit strong commonality as to the association between life-cycle stages and travel patterns. This 
association is in general in good agreement with the monetary expenditure patterns discussed in the previous section. Although a controversy does exist about whether one can improve the model's predictive capability by using a life-cycle variable in trip generation analysis (Kitamura and Kostyniuk 1986; McDonald and Stopher 1983; Simonsen and Neveu 1985), it is evident that analyzing travel patterns along life-cycle stages offers a rich depiction of household behavior.

Important in this context is the rapidly changing household structure with the increase of non-traditional families (Rosenbloom 1985): "Most conventional transportation planning methods do not reflect and respond to the growth and diversity of non-traditional families." The explanatory power offered by simple, conventional variables such as household size is seriously limited in light of the ongoing changes.

\section{Presence of children}

Empirical evidence is abundant that the presence and age of children in the household strongly influence its members' travel behavior. For example, Allaman et al. (1982) conclude that "such life-cycle effects as having preschool children present, having the youngest child reach school age, and progressing to other points in the life-cycle do indeed prompt changes in time allocation." Mobility indicators in general vary along a concave curve as the household progresses through life-cycle stages [exceptions are social-recreation trips (Kostyniuk and Kitamura 1986b) and the amount of time spent out of home and on travel by adult members of household, which decline as a household progresses through life-cycle stages (Kitamura et al. 1981)].

The presence of preschool children has a strong inhibiting effect, constraining the adult members' travel behavior, whereas households with school-age children have the highest person-trip rates (Allaman et al. 1982), partly because of the size of these households. Using a 1968 Washington, DC, data set, McGinnis (1978) examined the complex interaction among sex, employment, and presence of children. Households with children have higher total trip rates and non-work-trip rates. This is also the case for shopping trips and, of course, serve-passenger trips. McGinnis reports that families with children have slightly lower work-trip rates and, surprisingly, lower social-recreation-trip rates. In terms of household car trip generation, a study indicates that households with driving-age children generate the most car trips (Denk and Boyle 1982).

Similar patterns can be observed at the individual level: those with preschool children show lower trip rates, and those from households in which the youngest child is school age (5-17 years old) are the most mobile (Kitamura 1983; Kostyniuk and Kitamura 1986b). Participation in out-of-home activities shows the same concave curve along life-cycle stages (Stopher and Ergun 1979). Also commonly found is the tendency for individual mobility to decline in later stages of the life cycle (Kitamura 1983; Kostyniuk and Kitamura 1986b; Supernak 1983).

These findings support the notion that a change in the role played by an individual has a systematic impact on his travel behavior. In addition, the systematic variations observed along life-cycle stages at the individual level indicate the important effect that the interaction among household members exerts on each individual member's travel behavior.

Although common findings have emerged, it is a complex and unobservable process that determines the need to travel, the assignment of tasks across household members, and joint engagement in activities. The presence of conflicting findings in the literature is not surprising. For example, McGinnis (1978) notes that when the wife in a household is employed, the household's weekday discretionary activities decrease and certain activities 
are transferred from the wife to the husband, but that no significant change takes place in the total trips or total non-work trips made by the husband and wife when children are present. McGinnis concludes (1978):

In summary, the results indicate that the presence of children has little effect on the travel of the husband and wife in the household. The travel by the children, however, significantly increases total household travel.

\section{Single-person households}

Young single individuals are in general more mobile than married individuals in the same age group (Kitamura 1983; Stopher and Ergun 1979). In particular, single persons show greater participation rates in, and duration of, leisure activities (Pant and Bullen 1980), showing the outward orientation of their life-style. This tendency is more pronounced among single men than single women (Allaman et al. 1982). However, a study shows that single men and women have similar person-trip rates (Kostyniuk and Cleveland 1978). The mobility of individuals gradually declines as they move past the life-cycle stage in which they have school-age children; adults with older children generate fewer trips than those with school-age children, and older adults without children generate even fewer trips. A tabulation indicates that working single persons of at least 45 years old who have no children living with them have slightly lower trip rates than their married counterparts. Older single non-working persons, on the other hand, have higher trip rates than married non-working individuals (Kitamura 1983).

\section{Single parents}

An analysis based on census data indicates that of the 30 million families in the US with children under $18,19.5 \%$ are not headed by a married couple and that about $85 \%$ of these are headed by women (McKnight et al. 1986). Of all children under 6, 20.5\% lived with a single parent in 1982, which is up from 6.1\% in 1960 (US News and World Report 1983). Although only minimal work has been done on the transportation problems of single parents (McKnight et al. 1986; Raux and Rosenbloom 1986), recent studies nonetheless illustrate their travel characteristics.

Using Canadian large-scale data, Rutherford and Wekerle (1986) report that single mothers tend to be in the labor force more than do married women with children, but that their incomes tend to be below average. Consequently, car ownership rate is low among single parents. For example (McKnight et al. 1986), "of all female headed households with children under 18 in the City of Chicago, $65.1 \%$ do not own a vehicle." And, "nationally, $43 \%$ of all single parents in Canada did not have access to a car in 1982, contrasted with only $11 \%$ of all two-parent families with children under the age of 18" (Rutherford and Wekerle 1986). Combined with the lower rate of license holding among women (Kostyniuk and Kitamura 1987; Michaelson 1983), single parents' primary mode of travel tends to be public transit. For example, the bus is used more frequently in Chicago by single mothers for their work trips (McKnight et al. 1986).

Because single parents often perform both breadwinning and homemaking roles, they tend to be subjected to tighter time constraints (Fox 1983; Michaelson 1983; Rosenbloom 1985; Rutherford and Wekerle 1986). Presumably because of this, total trip rates of singleparent households are only marginally higher than those of nuclear families when their vehicle ownership patterns, age structure, and residence patterns are accounted for 
(Kostyniuk et al. 1989). The latter study concludes that the apparent lack of mobility of single parents is due to limited transportation resources (the automobile and the driver's license) available to them and that, given the availability of these resources, single parents make slightly more trips than their married counterparts. It is also noted that the activity patterns of (Rosenbloom 1985) "single working parents were not greatly different from comparable working women with spouses." There appears to be a consensus that, given the level of car ownership and license holding, single parents' travel patterns are not appreciably different from those of their married counterparts. Note, however, that this result may be due to conceivably lower survey response rates among single parents. In addition, it should be kept in mind that the analyses of observed travel behavior may not accurately reflect the travel needs of single parents.

Sex and employment status

The issue of sex, role, and travel behavior has received extensive attention in the past decade. Empirical results have been accumulated to illuminate behavioral differences between men and women; studies have focused on changes over time in travel behavior with the intent of identifying the trend and determining whether the "gender gap" is narrowing.

There are several well-accepted sex differences in travel behavior. Women make trips less frequently than men even when employment status is accounted for (Hanson and Hanson 1980; Kostyniuk and Kitamura 1986b; Madden and White 1978; Tardiff 1975). As noted earlier, single men are more mobile than single women, principally because of a higher frequency of entertainment trips and return-home trips (Allaman et al. 1982). It is also well established that women's trips tend to be shorter compared with men's (Hanson and Johnston 1985; Kostyniuk and Cleveland 1978), their travel-time expenditures tend to be less (Pendergast and Williams 1981), and they tend to be passengers rather than drivers, although this tendency varies with age (Hanson and Hanson 1980; Kostyniuk and Cleveland 1978).

There also exists the commonly found tendency for women in two-worker households to use public transit, walk more, and use the automobile less than do men (Hanson and Hanson 1980; Hanson and Johnston 1985). This tendency is not more pronounced among single parents (Raux and Rosenbloom 1986), suggesting that the woman's transit dependency is in part attributable to the allocation of the family cars among family members. McGinnis (1978) observes that "the allocation of the first car appears to be to the husband and the second car to the wife."

In short, women tend to be less mobile and more transit dependent. A question that arises is whether these tendencies are changing and sex differences are diminishing as more women gain employment and assume some of the household and societal roles that were once in the male domain. Before empirical results that offer clues to this question are reviewed, more characteristics of travel and time use patterns will be covered.

Previous studies have repeatedly pointed out that women have a higher shopping-trip rate. Women's trip rates for personal business and shopping are higher than those of men in the same life-cycle stages, especially among women from one-worker households (Hanson and Hanson 1980). Examining the percentage of trips by purpose controlled by employment, sex and life-cycle, a study notes that (McGinnis 1978) "the highest percentages of shopping trips are associated with suburban homemakers, next by the urban employed homemakers." Evidently "non-working wives have a higher participation rate for household support activities than do working spouses of either sex" (Pant and Bullen 1980). 
More generally, homemakers and individuals who are not employed engage in more non-work travel (Doubleday 1977; Hanson and Hanson 1981b). Women from one-worker households pursue more social-recreation, personal business, and shopping trips than do men (Kostyniuk and Kitamura 1986b). Substantial sex differences also exist in time use in addition to the well-recognized difference in travel-time expenditure (Kostyniuk and Kitamura 1986b; Madden and White 1978). An analysis of multi-country time-use data (Robinson et al. 1972) indicates that women spend more time than working men on household care (no data on non-working men are shown). Married working women spend less time on household care than their non-working counterparts, but they spend more time on this activity than do single working women. The time spent for household care increases with the number of children, so women with preschool children spend the least amount of time out of home and on travel (Kostyniuk and Kitamura 1986b). Finally, analyses of multi-day travel behavior have offered consistent indications that women's travel patterns are more variable over time than those of men (Jones and Clarke 1988; Pas and Koppelman 1986). This tendency is interpreted as an indication of sex differences in activity engagement and constraints.

These observations support the notion that the apparent sex differences in travel and time-use patterns are due to sex-based role assignment in which employment is a principal factor. The increasing labor force participation by women is evident from statistics. For example, the percentage of women in the civilian labor force increased from $42.6 \%$ in 1970 to $49.1 \%$ in 1978 . The increase is particularly noticeable among women with children (Rosenbloom 1985), which is reflected in the increased work-trip rate of women from households with preschool or school-age children (Kostyniuk and Kitamura 1986b). Although employed women tend to work fewer hours than do employed men (Robinson et al. 1972), it is obvious that the assignment of breadwinning and homemaking roles is now less sex-based. Is this change then reflected in the travel patterns of working men and women?

Many study results suggest that role assignment between men and women remains sexbased even when both are employed. For example, an analysis of Australian data (69) indicates that employed men spend more hours on work-related activities and commuting than do employed women. The average time expenditures by employed women on housework, shopping, and child care are $\sim 3,0.8$, and $0.5 \mathrm{~h}$ per day, respectively. The corresponding time expenditures by men are $<1,0.4$, and $0.3 \mathrm{~h}$, respectively.

This demand for housework and child care leads to less leisure time available to women. A study indicates that free time as a proportion of a 24-h day varies from $17 \%$ for housewives to $14 \%$ for employed men to $10 \%$ for employed women (Robinson et al. 1972). Wigan and Morris (1981) also note that employed men tend to have more free time on weekdays. Time expenditure for (out-of-home) recreation was obtained from 35-day diaries to be $9.4 \mathrm{~h}$ for women and $17.3 \mathrm{~h}$ for men for the 35-day period (Hanson and Hanson 1980). An analysis of Dutch, French, and US data sets also shows that leisure activity and visits are less frequent among female workers of two-worker households (Raux and Rosenbloom 1986).

Previous studies suggest that household responsibilities, which vary by the presence and age of children, do not have a strong impact on the activity patterns of men (Rosenbloom 1985). This is exemplified by the finding that life-cycle stage influences women's travel patterns much more significantly than it does men's (Kostyniuk and Kitamura 1986b), in particular, women's serve-passenger trips (Kitamura 1983). The presence of children has no impact on men or on women who are not employed; "for employed women, however, the transition to having a young child prompts less time in pleasure travel and more time 
spent in shopping" (Allaman et al. 1982). These findings all suggest that differences based on sex cannot be changed by the increasing labor-force participation of women.

Nevertheless, aspects of travel behavior and time use exist in which sex differences appear to be narrowing. For example, "for the household with only the male working, the wife provides the majority of the household support, whereas for the two-worker household, the husband does more of this activity" (Pant and Bullen 1980). Pas (1984) acknowledges that "the daily travel-activity patterns of adult males and females are differentially affected by the presence or absence of young children in the household", but maintains that the effect of employment supersedes this.

Although noting that "intra-household division of labor for out-of-home maintenance activities continued to be gender-based," Kostyniuk and Kitamura (1986b) also observed that sex differences are very small among two-worker households with preschool children; in fact, men in these households shop and pick up children slightly more frequently than do women. Although it is true that pronounced differences exist between women and comparably situated men and that "family and household responsibilities [are] strong motivators of women's travel and employment behavior" (Rosenbloom 1985), the increase in working women is necessarily changing role assignment within households and hence travel behavior of men and women.

The elderly

Individuals over the age of 65 are the fastest-growing group in the US. It is projected that by the year 2000 they will make up $13 \%$ of the population, and by 2030 this will increase to $21 \%$ (Spencer 1984). As some of the studies using life-cycle stages have shown earlier, the elderly have lower trip rates, although this is in part due to the absence of work trips among retired individuals. Allaman et al. (1982) report that "household members under 35 account for... about 2 more trips [per day] than those 65 and older."

Perhaps most important is capturing the changing behavioral patterns of the elderly. Wachs and his colleagues (Wachs and Blanchard 1976; Bunker et al. 1977) describe the stereotype of the elderly of today as living in higher-density areas, dependent on public transit, having a lower income, and being less mobile. The decline in mobility, however, may not be entirely attributable to the process of aging itself, but to the life-style that the cohort of the current elderly population long ago established. Wachs and Blanchard (1976) anticipate that "the elderly of the next 20 years will include many suburbanites, many drivers, and many who travel a great deal." Unfortunately, little empirical evidence exists to indicate the changing travel patterns of the elderly population.

Income, car ownership, and other factors

Household income, an obvious determinant of consumer expenditure patterns and therefore a determinant of life-style, has been one of the primal variables in travel demand analysis. Past studies have shown that higher income is associated with higher person-trip rates (Levinson 1976), more vehicular trips (Douglas 1973), more social trips (Tardiff 1975), increased work-trip length (Bellomo et al. 1970), and more frequent multi-stop trip chains (Kitamura et al. 1981). Recent studies include an analysis of daily travel frequency and distance by mode that shows clearly that the percentage of driver trips and driver trip distance increase with income, whereas passenger trip frequency and distance and the percentage of public transit trips decrease with income. Public transit trip distance, however, is at a minimum in the middle-income range, beyond which it increases with income, 
suggesting long-distance commuting trips made by higher-income individuals (Baanders et al. 1985).

Empirical results are also abundant in which income does not exhibit a logically consistent and statistically significant effect or is excluded from the model, presumably because of its insignificance. For example, Allaman et al. (1982) maintain that "income is not a significant determinant of total trip-making behavior, although it has marginal positive impact in the work and entertainment purposes," and income is not significantly associated with time allocation by employed individuals, although certain associations are found for time allocation by non-employed individuals.

The apparent lack of significance of income is presumably due to the fact that car ownership, which is strongly correlated with income, is more directly associated with travel behavior than is income. Being the consequence of a long-term household mobility decision, household car ownership reflects "a certain type of life-style which one cannot measure with existing household interview data" (Allaman et al. 1982). Accordingly, many aspects of travel behavior are conditionally independent of household income, given household car ownership.

Household car ownership is another primal variable in travel demand analysis (Federal Highway Administration 1975). Indeed, practically all models of trip generation and mode choice incorporate a car ownership or car availability variable (Kostyniuk and Kitamura 1986b). In general, higher levels of car ownership imply higher trip rates, increased car use, increased trip lengths, and more trip chaining (Denk and Boyle 1982; Doubleday 1977; Golob 1984; Kansky 1967).

A question of critical importance in this context is whether car ownership is a variable that explains observed variation in travel behavior, or whether it is a dependent variable that merely reflects a household's propensity to travel. Car ownership may be viewed more appropriately as a surrogate for unmeasured propensity to travel, part of which is attributable to life-style. The existing modeling approach using car ownership as a primal explanatory variable is adequate if the association between car ownership and travel behavior does not change substantially. Recent studies, however, indicate that this association does change over time and that the explanatory power offered by household car ownership declines as motorization progresses (Kitamura and Kostyniuk 1986; Kostyniuk and Kitamura 1986a). Thus, it is desired that the car ownership variable be replaced by another variable more intrinsically related to travel behavior.

Other factors that are less frequently used in travel behavior analysis, but are nonetheless relevant here, include education, ethnicity, and residence location. Education is used by Salomon (1983) as one of the dimensions along which the life-style orientation is defined. Past studies have found certain associations between education and travel behavior (Tardiff 1975). Allaman et al. (1982) found education to be associated with the time spent working, eating away from home, in entertainment, and in travel by employed individuals. Reviewing the literature on survey methods, Kitamura and Bovy (1987) suggest that the apparent positive effect of education on trip rates is in part due to reporting errors.

Ethnicity is used only occasionally in travel behavior analysis. For example, Nicolaidis et al. (1977) used language (English vs. French) as one of the segmentation bases applied to an Ottawa data set. Their "multidimensional demographics," based on language, age, home ownership, and sex, appear to capture the major dimensions of life-style. Available results suggest the presence of ethnic differences in trip rates and time use. Studies indicate that white individuals engage in social activities that require trips more frequently than do minority groups (Chapin 1978) and that differences based on ethnicity also exist in time use (Allaman et al. 1982). These observations are consistent with the hypothesis that 
(Reichman 1975) "cultural traits may account for different weights given to basic human needs, in a way not very different from differential weights caused by shifts in life-cycle, or in economic status." However, relatively little is known about the association between ethnicity and travel, possibly due to the multitude of ethnic and cultural backgrounds. In addition, the frequently observed correlation between ethnic background and socioeconomic status makes the isolation of an ethnic effect a difficult task.

Residential location is extremely relevant to the discussion if suburban lifestyle is the cause of urban congestion problems. Relatively little attention has been paid in travel demand analysis to the factors that influence choice of residential location. The key issue that needs to be addressed is how households trade off among commuting distance (and time), housing price, and various amenities that vary greatly by location. Among the preferred housing attributes are "better" neighborhood quality, better schools, a new house in a well-established neighborhood, a housing unit all on one floor, and a large lot (Butler et al. 1969). Obviously, these preferences are correlated with the life-cycle and life-style of the household. But what is the relation between housing preferences and household travel behavior? Unfortunately, little is known that might answer this question.

The existing results indicate that trip generation is negatively correlated with population density, suggesting geographical variations in life-style within a metropolitan area (Allaman et al. 1982; Monzon et al. 1988). The significant effect of home ownership found in several studies (McDonald and Stopher 1983) may again be viewed as an indication of the association between population density and travel behavior. An analysis of daily travel patterns concludes that (Pas 1984) "those residing in low-density areas are significantly more likely to undertake a multi-step daily pattern."

Although some insights are already available, more detailed and extensive examination is desirable on the subject of life-style and residential location.

Analyses in this subject area have not advanced, possibly because of the conviction that there exist spatially invariant trip generation rates and that trip generation models are geographically transferable. Attempts to determine the effects of accessibility on trip generation have shown only minor results (Nakkash and Grecco 1972; Zimmerman et al. 1974). Thus, the conventional planning models implicitly assume that households of given characteristics will exhibit the same travel patterns no matter where they are located.

Still another problem is that many attributes of a metropolitan area, including transportation service levels and characteristics of household members and their preferences, are spatially correlated. Because of this, cases of ecological fallacy are the likely consequences of a marginal analysis of travel characteristics in which a limited number of contributing factors is controlled for. Because of these limitations, it is not possible to determine whether a particular travel pattern exhibited by a household is due to the household's life-style aspiration or to residence location and car ownership.

A very fundamental question is whether travel behavior is conditionally independent of life-style orientation, given residence location, car ownership, and other measurable factors. An answer to this question will determine the importance of the life-style concept in travel demand forecasting and where in the forecasting process the concept can contribute most.

\section{Extrapolation}

How useful is this information on behavioral characteristics of population subgroups? Is adequate information available to determine likely future travel demand? If so, what does the available evidence indicate as future pictures of urban travel? In this section, the 
discussion is concerned with the usefulness of existing empirical findings in long-range forecasting.

It is important to distinguish two types of changes that may take place in the future:

- Shift of behavioral units across life-style segments.

- Shift in the behavioral pattern of each life-style segment.

Demographic trends offer strong indications that household size and structure, laborforce participation, car ownership, license holding, and age distribution will continue to change (81). If the magnitude of these changes can be determined and future life-style segment sizes can be estimated with reasonable accuracy, and if the behavior of each segment remains stable over time, then the available evidence as summarized in the previous section should offer useful long-range forecasts of travel demand. In this section, characteristics of future travel demand as inferred from observed travel patterns of population segments are briefly summarized.

\section{Sociodemographic Changes}

The salient trends in household size and structure have been summarized by Spielberg et al. (1980) as a sharp decline in the average size of households (3.33 persons in 1960 to 2.78 in 1979) and an increase in single-person households, an increase in the proportion of non-family households and single-parent households, a dramatic increase in the number of suburban households, and a slow increase in central city households of smaller sizes. The percentage of married couples with children is gradually declining, that of married couples without children remains stable, and the fraction of individuals living alone steadily increases in all age groups (Spielberg et al. 1980, 1981). The labor-force participation by women has been increasing, resulting in an increasing proportion of two-worker households with young children (Kostyniuk and Kitamura 1986b).

These trends are reflected in the changing distribution of life-cycle stages, with a much smaller proportion of households with children in recent years (Kostyniuk and Kitamura 1984). Resulting changes in travel demand that can be inferred using the travel characteristics of life-style segments (Kostyniuk and Kitamura 1986b) are increases in:

- The number of work trips because of an increase in working women.

- The number of person trips because of an increase in young, single individuals.

- The number of social-recreation trips because of an increase in single individuals and young couples without children.

- The number of person trips and total travel time expenditure by women because of an increase in the number of two-worker households.

Likewise, there will be decreases in:

- The number of person trips and number of serve-passenger trips by married women in both one-worker and two-worker households because of a decreasing number of households with children.

- The number of shopping trips by women from one-worker households because of the decreasing number of one-worker households with children.

- Mobility because of the increased number of households consisting of older individuals.

In addition, on the basis of the information available at this point, the increasing number of single-parent households will lead to a decline in mobility due primarily to the lower 
levels of car ownership and license holding by single mothers. The combined effects of these changes cannot be determined without performing a formal analysis that explicitly incorporates changes in segment sizes in the population.

In addition to an increase in the number of work trips, an increase in two-worker households will lead to changes in trip rates by purpose, linking of trips, trip timing, and destination locations. For example, it is typical for shopping and work to be combined in working women's trip chains (83). This may involve changes in the destination and timing of the shopping trip. A thorough assessment of the impact of the increased number of twoworker households requires a comprehensive investigation of daily travel behavior by oneworker and two-worker households, including geographical and temporal aspects.

Car ownership and license holding

Ownership and use of the automobile in the US increased dramatically after World War II. The percentage of households that did not have access to cars decreased from $41 \%$ in 1950 to $13 \%$ in 1980 . The percentage of households with two or more cars available increased from 7 to 52\% during the same period (Kostyniuk and Kitamura 1986b).

Approximately $85 \%$ of the adult population is currently licensed to drive, and the proportion of license holders among those 25-35 has reached $96 \%$. As the driving population expanded, its age and sex composition changed. In 1940, only $25 \%$ of all drivers in the US were 40 or older and $1.7 \%$ were over 65 . In 1983, about $45 \%$ of the drivers were over 40, about $24 \%$ were over 55, and $11 \%$ were over 65 (Kostyniuk and Kitamura 1987). An estimate indicates that by 2000, 28\% of all drivers will be over 55 and by 2050, this proportion will be 39\% (Federal Highway Administration 1986).

According to the Federal Highway Administration, an estimated 152 million individuals were licensed to drive in 1983 . The number of male drivers increased by 2.9 million, from 76.6 million in 1979 to 79.5 million in 1983. During the same period, the number of female drivers increased by 6.1 million from 66.5 to 72.6 million. The proportion of female drivers in the total driving population was $30 \%$ in 1960, which increased to $43 \%$ in 1970 (Hulbert 1976) and $47.7 \%$ in 1983 . The proportion of female drivers in 1983 varied slightly by age group. The youngest age group, less than 20 years old, made up $46.4 \%$ of the total driving population. The proportion increased with age, peaked with $48.5 \%$ observed for those 40 44, and then declined. Sex differences in license holding thus appear to be diminishing.

Statistics are abundant showing that household car ownership or car availability is positively correlated with trip generation (Kostyniuk and Kitamura 1986b; Levinson 1976; Supernak 1983), although the effect of car ownership may be exaggerated because trips by non-mechanized modes are not included in the analysis. Whether or not trip generation increases further if household car ownership continues to increase needs to be critically examined. As noted earlier, it can be argued (Kitamura and Kostyniuk 1986) that car ownership does not serve as a strong indicator of a household's propensity to travel once motorization has reached a mature stage in which a household can easily adjust the number of automobiles because of decreasing real costs of car ownership and maintenance (Horn and Matthews 1983). Recent tabulations, in fact, indicate that car ownership variables are not necessarily significant in trip generation models (Kitamura and Bovy 1987; Monzon et al. 1988).

It is logical that if an overall increase in household car ownership is primarily due to an increase in the number of cars owned by multi-car households, then its impact on trip generation may be limited. With the high level of car ownership in the US, the acquisition of a new car may often imply that the number of cars exceeds the number of drivers in the 
household. In this context, it is important to note that highly mobile households tend to include teenage drivers in addition to adult drivers (Denk and Boyle 1982); the number of drivers may be a better indicator of trip generation and car use by a household. In a recent simulation analysis using a dynamic model system of household car ownership, trip generation, and mode use, the number of drivers was shown to be the most crucial determinant of car and public transit use. Despite the overwhelming empirical evidence that car ownership is positively associated with trip generation and car utilization, the impact of increasing car ownership needs to be critically evaluated.

\section{Changes in the travel environment}

The basis of the discussion in the previous section is the assumption that the travel behavior of each segment will remain unchanged over time. Possible shifts in behavioral patterns within each life-style segment will be discussed to determine whether this assumption is plausible.

Changes anticipated are not limited to sociodemographic characteristics, but will involve many elements of the travel environment: transportation supply characteristics, land use patterns, housing supply, retail distribution systems, service and entertainment industries, new consumer technology and products, telecommunications systems, and forms of employment and performing work. It is inevitable that these changes will influence and transform the life-styles of urban residents.

\section{Consumer technologies and products}

Consumer technology has shown a drastic change in the past few decades. Such home appliances as washing machines, dryers, refrigerators, freezers, dishwashers, and, more recently, microwave ovens are now prevalent in American homes. A wide variety of prepared food is available, and food preparation can be speeded up by electric and electronic kitchen gadgetry. One would expect that the time spent in homemaking had substantially decreased because of these advances.

Contrary to this expectation, a study indicates that the domestic workload for urban women has not decreased appreciably over time, despite these technological advances. Observing time-series data from three different sources, Wigan and Morris (1981) conclude that: "While modest time savings have been made in some types of domestic work, others (including shopping) seem to demand more time than before." Unfortunately, information is virtually absent to assess the impact of household appliances on urban travel, this aspect of urban living having been traditionally outside the scope of travel behavior analyses.

Home entertainment has also changed drastically; there is now a television set in virtually every home. More recently, video games, videocassette recorders, big-screen television sets, cable television, and a variety of home computers have been introduced into American homes. Concurrent with this, video rental outlets are mushrooming in suburban shopping centers. It seems as if "home-based leisure" (Maloney 1982) is replacing traditional out-of-home social recreation activities.

An analysis of the temporal stability in trip generation indicates a decrease in the number of social-recreation trips made during the evening (Kostyniuk and Kitamura 1984, 1986b). This suggests that out-of-home social and recreational activities have been replaced by in-home activities using home entertainment devices. The impact of home 
entertainment devices on travel is again difficult to assess because of the lack of adequate data and also because these devices may induce new trips such as visits to a video rental store to pick up movie cassettes (Kitamura 1988b).

\section{Telecommunications}

Rapid advances are being made in telecommunications technology. New telecommunications capabilities now available offer the potential of replacing certain shopping and personal business trips. Through the use of home computers or television sets, consumers can shop electronically for an increasing variety of goods and services. Bank transactions can be made from home using the telephone. The potential travel impact of the evolving telecommunications technology has been reviewed by Salomon (1986).

These developments have made telecommuting a realistic alternative to commuting. Permitting workers to perform their tasks without leaving their homes, telecommuting will have an immediate and substantial impact on the travel behavior of workers and their family members. In addition, telecommuting will have a long-term effect on the spatial and organizational structures of many economic and social activities. New forms of employment are likely to emerge, allowing telecommuting workers to engage in part-time employment with multiple employers that may be scattered throughout the country; telecommuting lifts geographical constraints that have so long bound the location decision of both employers and workers, possibly leading to new urban forms.

The potential of telecommuting in relieving traffic congestion, reducing energy consumption, mitigating air pollution, and saving infrastructure construction and maintenance costs remains to be determined. Unfortunately, assessments of the impact of telecommunications technology on life-style, residential location, and travel demand tend to be educated guesses. One critical difficulty is the lack of data that can support the effort to determine whether in-home activities may substitute for out-of-home activities, whether out-of-home activities will be suppressed, or whether new out-of-home activities will be induced as a result of new telecommunications technology.

An excellent opportunity for this assessment is offered by an ongoing experiment by the State of California that began in January 1988. The pilot project involves $\sim 200$ volunteer state workers who will telecommute and about the same number of conventional commuters as a control group. Information on household travel behavior will be obtained through 3-day travel diary surveys to be conducted in January 1988 (before telecommuting begins), in January 1989, and in January 1990. These observations will provide an invaluable database for analysis of the short-term impact of telecommuting on travel and life-style.

\section{Urban system}

As suburbanization continues without adequate levels of investment in infrastructure, suburban congestion has emerged as a new focus of the urban transportation planning effort. Retail activities appear to be congregating in increasingly larger suburban shopping malls and extremely labor-efficient discount outlets. The continuing growth of suburbs is shown in demographic statistics (Spielberg et al. 1980, 1981), in housing output (Bureau of Economic Analysis 1986), and by the suburban congestion problem itself. Return to the central city is a movement often noted (Anderson 1987), but its magnitude has never been comparable with that of the explosive move toward the suburbs. Will suburbanization continue indefinitely? Will urbanites continue to aspire to suburban life-styles? Will there be a turning point? 
European countries are also experiencing the same trend of suburbanization. Their assessment is (Webster et al. 1985):

The locations of both homes and employment will become much more dispersed and urban densities will continue to fall. The shift from heavy engineering (industry) towards high technology manufacturing and the service industries, and the development of information technology will lend impetus to this process.

Therefore, trips will be dispersed more uniformly, and the central cities will continue to decline (90). Serious concern is voiced that "transport and land use policies seem capable of exerting only a relatively weak influence on the prevailing trends in urban structure and transport choice... It seems likely that public transport use in most places will eventually reach a peak value and then experience decline" (Webster et al. 1985) as it did in many metropolitan areas in the US.

If American households are eternally to aspire to a more spacious life-style, then the ongoing suburbanization process can be curbed only by an increase in the cost of pursuing this life-style. Although European researchers observe that (Webster et al. 1985) "the inner city generally contains some high-class residential areas, and social attitudes generally are more likely to result in the maintenance of the urban way of life," the advanced stage of suburbanization in the US suggests that the attraction of the central city is generally lacking. If the trend of suburbanization were to stop, it would presumably be because of the cost of suburban lifestyles rather than the attraction of the inner city.

Two increasing cost elements are travel time and housing. It is not clear whether suburbanization increases or decreases commuting travel time; it is conceivable that commuting distance, and possibly commuting time, will decline as suburbanization transforms the once-typical radial commuting pattern between suburb and central city to a more uniformly distributed spatial pattern. Suburban congestion may not act as a deterrent to suburbanization. Increasing housing prices, however, may motivate a larger fraction of households to seek housing alternatives in high-density areas. In particular, an increasing number of couples without children are turning to urban life-styles.

\section{New values and life-style}

There are additional elements that may influence life-style and travel behavior of urban residents importantly in the future. Behind the abundance of consumer products, including the automobile, is the increasing level of real income. Increasing discretionary expenditures will generate demand for new types of goods and services, increased awareness of health and physical conditions, and demand for educational and cultural activities.

Life-style will continue to evolve with the aging of the cohorts of individuals who had acquired life-styles and travel habits in which the automobile played a central role. Social attitudes toward sex roles are changing. Waves of immigrants constantly bring in their own cultures and life-styles. New values continue to emerge and form new lifestyles. Although the issues of changing sex roles and the new elderly have been well recognized, analytical efforts by transportation planners tend to be motivated by the desire to prove that travel behavior is stable and that travel demand models remain valid over time. This discussion of the many changes that are pertinent to travel behavior indicates that future effort must focus on understanding and predicting the direction and magnitude of behavioral changes. 


\section{Discussion}

A solid body of empirical evidence exists on the travel characteristics of population segments defined in terms of life-cycle stage, sex, employment, income, age, car ownership, and license holding. Empirical results are in general consistent and portray differences in life-style across the segments.

If the life-style and travel behavior of each segment remain stable, the knowledge available now can readily be applied to forecast future travel demand once the future population size of the segment has been forecast. The results of an initial attempt to obtain qualitative trends were presented in the section on extrapolation.

Aspects of travel behavior that have been examined in the past tend to be limited, however. Although trip generation, trip length, travel mode, and time use have often been investigated to form an accumulation of comparable findings, only isolated analyses exist on other aspects, such as timing of trips, vehicle occupancy (which is correlated with joint activity participation by household members), trip destination, and linking of trips. Little is known about how these travel attributes change in response to changes in the travel environment.

Further effort is needed to investigate the characteristics of behavioral changes. Past efforts have tended to emphasize behavioral stability rather than behavioral change. Behavioral changes are not usually viewed as a process of adaptation, that is, the process in which an individual or a household makes conscious decisions and adjusts to a new set of conditions in the travel environment. The concept of life-style will be useful in the analysis of adaptation patterns.

More attention also needs to be devoted to change in life-style and resulting change in travel behavior. Numerous elements in the travel environment change continuously. New consumer products appearing constantly on the market greatly reduce the time spent in homemaking; home entertainment equipment is enriching in-home leisure activities; institutional and technological changes are transforming the way urban residents work, and social attitudes and values are evolving. How these changes will transform life-style and affect travel demand is difficult to assess at this point. A research effort must be initiated for this assessment that will call for new conceptual frameworks, survey formats, and analytical structures.

Some of the tasks and issues involved in this future effort are as follows:

- In order to study adaptation behavior adequately, more detailed characterization of travel behavior is necessary. Furthermore, the characteristics of changes in travel behavior over time must be identified. Available origin-destination survey data should be used for extended assessment of behavioral characteristics and their changes over time.

- The adequacy of the standard approach in life-style analysis (i.e., identification of sample segments using available socio-economic measurements) must be critically examined. The variation in life-style that can be accounted for by adopting such a segmentation scheme may be limited. Analytical methods need to be developed to account for individuality, or idiosyncrasy, in life-style.

- It is likely that the life-styles of population segments evolve over time. It is essential that dynamic viewpoints be adopted to capture such changes. The conventional method of inferring behavioral changes over time on the basis of cross-sectional variations may not offer useful insights and accurate forecasts (Goodwin 1986; Kitamura and van der Hoorn 1987). More extensive use should be made of existing origin-destination survey 
results as repeated cross-sectional observations. This type of data set, already collected and readily available, will offer useful information on the changing sex roles and travel behavior of new elderly populations. In addition, it is desirable that an effort be initiated to establish a panel of households for longitudinal analysis of life-style and travel behavior to gain a better understanding of and predictive capability for future life-style and travel behavior.

- The emphasis on changes and adoption of dynamic viewpoints calls for alternative methods for demand forecasting as well as data collection. Promising is stochastic simulation of household behavior using dynamic models applied to sample panel households (which may be expanded with synthetically generated sample households). The feasibility and potential benefits of such new forecasting methods should be investigated. In addition, methods to forecast future demographic characteristics, especially such pertinent variables as life-cycle stage, need to be developed.

Acknowledgments Some of the results reported in this paper stemmed from research projects that were supported by the Rockefeller Foundation and the National Science Foundation. The author benefited from the comments he received from Lidia Kostyniuk on an earlier version of this paper.

\section{References}

Allaman, P.M., Tardiff, T.J., Dunbar, F.C.: NCHRP Report 250. New Approaches to Understanding Travel Behavior. TRB, National Research Council, Washington, DC (1982)

Anderson, K.: Spiffing up the urban heritage. Time Magazine. 23 November 1987, pp. $72-83$ (1987)

Baanders, A., Kremer-Nass, J., Ruijgrok, C.J.: Income decline and travel behaviour: some recent Dutch findings and research orientations. In: Jansen, G.R.M., et al. (eds.) Transportation and Mobility in an Era of Transition, pp. 37-53. Elsevier, Amsterdam (1985)

Bellomo, S.J., Dial, R.B., Voorhees, A.M.: NCHRP Report 89: Factors, Trends, and Guidelines Related to Trip Length. Highway Research Board, National Research Council, Washington, DC (1970)

Brail, R.K., Chapin, F.S.: Activity patterns of urban residents. Environ. Behav. 5, 163-190 (1973)

Bunker, J.B., Blanchard, R.D., Wachs, M.: Life-styles and transportation patterns of the elderly in Los Angeles. Transp. Res. Rec. 660, 1-11 (1977)

Bureau of Economic Analysis: The National Income and Product Accounts of the United States, 1929-82: Statistical Tables. US Department of Commerce, Washington, DC (1986)

Bureau of Labor Statistics: Consumer Expenditure Survey: Diary Survey, 1982-83. Bulletin 2245. US Department of Labor, Washington, DC (1986a)

Bureau of Labor Statistics: Consumer Expenditure Survey: Interview Survey, 1982-83. Bulletin 2246. US Department of Labor, Washington, DC (1986b)

Butler, E.W., Chapin, F.S., Hemmens, G.C., Kaiser, E.J., Stegman, M.A., Weiss, S.F.: NCHRP Report 81: Moving Behavior and Residential Choice: a National Survey. Highway Research Board, National Research Council, Washington, DC (1969)

Chapin, F.S.: Human time allocation in the city. In: Carlstein, T. (ed.) Human Activity and Time Geography. Timing Space and Spacing Time, vol. 2. Edward Arnold, London (1978)

Chicoine, J.E., Boyle, D.K.: Life-cycle concept: a practical application to transportation planning. Transp. Res. Rec. 987, 1-7 (1984)

Damm, D.: Theory and empirical results: a comparison of recent activity-based research. In: Carpenter, S.M., Jones, P.M. (eds.) Recent Advances in Travel Demand Analysis, pp. 137-162. Gower, Aldershot (1983)

de La Morsanglière, H., Raux, C.: Structure of the family and trip behavior. Presented at the World Conference on Transport Research, Hamburg (1983)

Denk, E., Boyle, D.: Life Cycle Characteristics of High Travel Households. TIR 15. New York State Department of Transportation, Albany (1982)

Dettelback, C.G.: In the Driver's Seat: the Automobile in American Literature and Popular Culture. Greenwood, Westport (1976) 
Doubleday, C.: Some studies of the temporal stability of person trip generation models. Transp. Res. 11, 255-263 (1977)

Douglas, A.: Home-based trip end models_ a comparison between category analysis and regression analysis procedures. Transportation 2, 53-70 (1973)

Federal Highway Administration: Trip Generation Analysis. US Department of Transportation, Washington, DC (1975)

Federal Highway Administration.: Traffic control design elements for accommodating drivers with diminished capacity. Request for proposal DTFH61-86-R-00044. US Department of Transportation, Washington, DC (1986)

Flink, J.J.: The family car. ITS Rev. 10(3), 4-8 (1987)

Fox, M.B.: Working women and travel: the access of women to work and community facilities. J. Am. Plan. Assoc. 49(2), 156-170 (1983)

Golob, T.F.: A descriptive analysis of trip chaining behavior in the Netherlands. In: Proceedings, Seminar H, PTRC Summer Annual Meeting, PTRC Education and Research Service, London (1984)

Golob, T.F., Zondag, E.R.: A causal model of mobility. In: Bovy, P.H.L. (ed.) Transportation and Stagnation: Challenges for Planning and Research, vol. 2, pp. 265-279. Colloquium Vervoersplanologisch Speurwerk, Delft (1983)

Golob, J., Schreurs, L., Smit, J.: The design and policy applications of a panel for studying changes in mobility over time. In: Behavioral Research for Transport Policy, VNU Science Press, Utrecht (1986)

Goodwin, P.: Some problems in activity approaches to travel demand. In: Carpenter, S., Jones, P. (eds.) Recent Advances in Travel Demand Analysis, pp. 470-474. Gower, Aldershot (1983)

Goodwin, P.B.: A panel analysis of changes in car ownership and bus use. Traffic Eng. Control. 27, 519-525 (1986)

Gunn, H.F.: An analysis of travel budgets into mandatory and discretionary components. In: Proceedings, Seminar N, PTRC Summer Annual Meeting. PTRC Education and Research Services, London, pp. 4964 (1981)

Hanson, S., Hanson, P.: Gender and urban activity patterns in Uppsala, Sweden. Geogr. Rev. 70, 291-299 (1980)

Hanson, S., Hanson, P.: The travel-activity patterns of urban residents: dimensions and relationships to sociodemographic characteristics. Econ. Geogr. 57, 332-347 (1981a)

Hanson, S., Hanson, P.: The impact of married women's employment on household travel patterns: a Swedish example. Transportation 19, 165-183 (1981b)

Hanson, S., Johnston, I.: Gender differences in work-trip length: explanations and implications. Urban Geogr. 6, 193-219 (1985)

Havens, J.J.: New approaches to understanding travel behavior: role, life-style, and adaptation. In: Stopher, P.R., et al. (eds.) New Horizons in Travel Behavior. Lexington, Lexington (1981)

Horn, B., Matthews, R.: International trends in car ownership and prospects for the future in OECD Member Countries. Presented at the 62nd Annual Meeting of the Transportation Research Board, Washington, DC (1983)

Hulbert, S.: Driver and pedestrian characteristics. In: Baerwald, J.E. (ed.) Transportation and Traffic Engineering Handbook, pp. 38-72. Prentice Hall, Englewood Cliffs (1976)

Jones, P.M., Clarke, M.: The significance and measurement of variability in travel behaviour: a discussion paper. Transportation 15(1/2), 65-87 (1988)

Jones, P.M., Dix, M.C., Clarke, M.I., Heggie, I.G.: Understanding Travel Behaviour. Gower, Aldershot (1983)

Kansky, K.J.: Travel patterns of urban residents. Transp. Sci. 1, 261-285 (1967)

Kitamura, R.: "Serve passenger" trips as a determinant of travel behaviour. In: Carpenter, S., Jones, P. (eds.) Recent Advances in Travel Demand Analysis, pp. 137-162. Gower, Aldershot (1983)

Kitamura, R.: Formulation of trip generation models using panel data. Transp. Res. Rec. 1203, 60-68 (1988a)

Kitamura, R.: An evaluation of activity-based travel analysis. Transportation 15, 9-34 (1988b)

Kitamura, R., Bovy, P.H.L.: Analysis of attrition biases and trip reporting errors for panel data. Transp. Res. 21A, 287-302 (1987)

Kitamura, R., Kostyniuk, L.P.: Maturing motorization and household travel: the case of nuclear-family households. Transp. Res. 20A, 245-260 (1986)

Kitamura, R., van der Hoorn, T.: Regularity and irreversibility of weekly travel behavior. Transportation 14, 227-251 (1987)

Kitamura, R., Kostyniuk, L.P., Uyeno, M.J.: Basic properties of urban time-space paths: empirical tests. Transp. Res. Rec. 794, 8-19 (1981) 
Kostyniuk, L.P., Cleveland, D.E.: Gender-role identification in the methodology of transportation planning. In: Rosenbloom, S. (ed.) Women's Travel Issues: Research Needs and Priorities. Research and Special Programs Administration, US Department of Transportation, Washington, DC (1978)

Kostyniuk, L.P., Kitamura, R.: Life cycle and household time-space paths: empirical investigation. Transp. Res. Rec. 879, 28-37 (1982)

Kostyniuk, L.P., Kitamura, R.: Temporal stability of urban travel patterns. Transp. Policy Decis. Mak. 2, 481-500 (1984)

Kostyniuk, L.P., Kitamura, R.: Changing effects of automobile ownership on household travel patterns. Transp. Res. Rec. 1085, 27-33 (1986a)

Kostyniuk, L.P., Kitamura, R.: Household lifecycle: predictor of travel expenditure. In: Behavioural Research for Transport Policy. VNU Science Press. Utrecht, pp. 343-362 (1986b)

Kostyniuk, L.P., Kitamura, R.: Effects of aging and motorization on travel behavior: an exploration. Transp. Res. Rec. 1135, 31-36 (1987)

Kostyniuk, L.P., Kitamura, R., Goulias, K.: Mobility of single parents: what do the trip records show? Spec. Transp. Plan. Pract. 3(3), 203-217 (1989)

Ladd, W.M., Larson, R.H., Boka, K.: A Trip Generation Model for the Detroit Region. Regional Transportation and Land Use Study, Detroit, MI (1969)

Levinson, H.S.: Urban travel characteristics. In: Baerwald, J.E. (ed.) Transportation and Traffic Engineering Handbook, pp. 138-206. Prentice Hall, Englewood Cliffs (1976)

Madden, J.F., White, M.J.: Women's work trips: an empirical and theoretical overview. In: Rosenbloom, S. (ed.) Women's Travel Issues: Research Needs and Priorities. Research and Special Programs Administration, US Department of Transportation, Washington, DC (1978)

Maloney, L.D.: Now, it's the "stay at home society". US News and World Report, 28 June 1982, pp. 64-66 (1982)

McDonald, K., Stopher, P.R.: Some contrary indications for the use of household structure in trip-generation analysis. Transp. Res. Rec. 944, 92-100 (1983)

McGinnis, R.G.: Influence of employment and children on intra-household travel behavior. In: Rosenbloom, S. (ed.) Women's Travel Issues: Research Needs and Priorities. Research and Special Programs Administration, US Department of Transportation, Washington, DC (1978)

McKnight, C.E., Savar, N.L., Paaswell, R.E.: Travel behavior of female single parents in the Chicago region. Presented at the 65th Annual Meeting of the Transportation Research Board, Washington, DC (1986)

Michaelson, W.: The impact of changing women's roles on transportation needs and usage. Institute of Transportation Studies, University of California, Irvine (1983) (available through National Technical Information Service, Springfield, VA)

Monzon, J., Goulias, K., Kitamura, R.: Trip Generation Models for Infrequent Trips. Department of Civil Engineering, University of California, Davis (1988)

Nakkash, T.Z., Grecco, W.L.: Activity-accessibility models of trip generation. Highway Res. Rec. 392, 98110 (1972)

Nicolaidis, G.C., Wachs, M., Golob, T.F.: Evaluation of alternative market segmentations for transport planning. Transp. Res. Rec. 649, 23-31 (1977)

Pant, P.D., Bullen, A.G.R.: Urban activities, travel and time: relationships from national time-use survey. Transp. Res. Rec. 750, 1-6 (1980)

Pas, E.I.: The effect of selected sociodemographic characteristics on daily travel-activity behavior. Environ. Plan. A 16, 571-581 (1984)

Pas, E.I.: State of the art and research opportunities in travel demand: another perspective. Transp. Res. 19A(5/6), 460-464 (1985)

Pas, E.I., Koppelman, F.S.: An examination of the determinants of day-to-day variability in individuals' urban travel behavior. Transportation 13, 183-200 (1986) (reprinted with corrections, vol. 14, pp. 320)

Pendergast, L.S., Williams, R.D.: Individual travel time budgets. Transp. Res. 15A, 39-46 (1981)

Raux, C., Rosenbloom, S.: Employment, childcare and travel behavior: France, The Netherlands, The United States. In: Behavioral Research for Transport Policy. VNU Science Press, Utrecht, pp. 363-380 (1986)

Reichman, S.: Travel adjustments and life styles—a behavioral approach. In: Stopher, P.R., Meyburg, A.H. (eds.) Behavioral Travel-Demand Models. Lexington Books, Lexington (1975)

Reichman, S.: Instrumental and life-style aspects of urban travel behavior. Transp. Res. Rec. 649, 38-42 (1977) 
Robinson, J.P., Converse, P.E., Szalai, A.: The everyday life in twelve countries. In: Szalai, A. (ed.) The Use of Time: Daily Activities of Urban and Suburban Populations in Twelve Countries, pp. 113-144. Mouton, The Hague (1972)

Rosenbloom, S.: The growth of non-traditional families: a challenge to traditional planning approaches. In: Jansen, G.R.M., et al. (eds.) Transportation and Mobility in an Era of Transition, pp. 75-96. Elsevier, Amsterdam (1985)

Rutherford, B., Wekerle, G.: Single parents in the suburbs: mobility patterns and access to transportation. Presented at the 65th Annual Meeting of the Transportation Research Board, Washington, DC (1986)

Salomon, I.: Life style-a broader perspective on travel behavior. In: Carpenter, S., Jones, P. (eds.) Recent Advances in Travel Demand Analysis. Gower, Aldershot (1983)

Salomon, I.: Telecommunications and travel relationships: a review. Transp. Res. 20A, 223-238 (1986)

Salomon, I., Ben-Akiva, M.: The use of the life-style concept in travel-demand models. Environ. Plan. A 15, 623-638 (1983)

Sharp, D.P.: Projections of automobile ownership and use based on household life-style factors. Report ORNL/SUB-7356/1. Oak Ridge National Laboratory, Oak Ridge, TN (1979) (distributed by National Technical Information Service, US Department of Commerce, Springfield, VA)

Simonsen, J., Neveu, A.J.: A comparison of life-cycle and family size variables in trip generation analysis to assess predictive capability. Transportation Analysis Report 48. New York State Department of Transportation, Albany (1985)

Skinner, L.E.: Family composition and life style variable use in urban transportation planning. Draft report. Federal Highway Administration, US Department of Transportation, Washington, DC (1984)

Spencer, G.: Projection of the population of the United States by age, sex, and race: 1983 to 2080. Current Population Reports. Bureau of the Census, US Department of Commerce, Washington, DC (1984)

Spielberg, F., Andrle, S., Ernst, U., Kemp, M.: Impact of demographic and migration trends on future travel in metropolitan areas. Assistant Secretary for Policy and International Affairs, US Department of Transportation, Washington, DC (1980)

Spielberg, F., Weiner, E., Ernst, U.: The shape of the 1980s: demographic, economic and travel characteristics. Transp. Res. Rec. 807, 27-34 (1981)

Stopher, P.R., Ergun, G.: Population segmentation in urban recreation choices. Transp. Res. Rec. 728, 59-65 (1979)

Supernak, J.: Travel time budget: a critique. In: Carpenter, S., Jones, P. (eds.) Recent Advances in Travel Demand Analysis, pp. 401-422. Gower, Aldershot (1983)

Tardiff, T.: Comparison of effectiveness of various measures of socio-economic status in models of transportation behavior. Transp. Res. Rec. 534, 1-9 (1975)

US News and World Report.: One-parent family: the troubles-and the joys. 28 November 1983, p. 57 (1983)

Wachs, M., Blanchard, R.D.: Life-styles and transportation needs of the elderly in the future. Transp. Res. Rec. 618, 19-24 (1976)

Webster, F.V., Bly, P.H., Johnston, R.H., Paulley, N., Dasgupta, M.: Changing patterns of urban travel. European Conference of Ministers of Transport, distributed by OECD Publications Office, Paris, France (1985)

Wigan, M.R., Morris, J.M.: The transport implications of activity and time budget constraints. Transp. Res. 15A, 63-86 (1981)

Zimmerman, C.A.: The life cycle concept as a tool for travel research. Transportation 11, 51-69 (1982)

Zimmerman, S., West, M., Kozlowski, T.: Urban highways as traffic generators. Federal Highway Administration, US Department of Transportation, Washington, DC (1974)

\section{Author Biography}

Ryuichi Kitamura is Associate Professor of Civil Engineering, University of California at Davis. Before his appointment at the University of California, he was a Research Assistant at the University of Michigan. His research areas include travel behavior, life-styles, and socioeconomic factors of urban travel choice. 